\title{
Ethical Marketing in the Blockchain-Based Sharing Economy: Theoretical Integration and Guiding Insights
}

\author{
Teck Ming Tan ${ }^{1} \cdot$ Jari Salo ${ }^{2}$
}

Received: 19 April 2021 / Accepted: 5 December 2021 / Published online: 16 December 2021

(c) The Author(s) 2021

\begin{abstract}
Since the introduction of Ethereum in 2015, blockchain technology (BT) has been evolving, and BT has been associated with the concept of the sharing economy by business academics. Despite the marketing research on the sharing economy that has been extensively conducted in the last decade, the linkage between BT and ethical marketing in the sharing economy remains unclear. Through a systematic literature review of 163 articles and a co-citation analysis, this study identifies the key elements of blockchain capabilities, blockchain attributes, and the underlying economic theories of blockchain. It also synthesizes and proposes a shift of ethical marketing logic in the blockchain-based sharing economy that delineates the principles of stakeholder capitalism. The article concludes with a list of future research directions that underline three approaches of stakeholder theory (i.e., the descriptive, instrument, and normative approaches). These directions aim to guide marketing scholars concerning how BT enables an institutionally embedded view of ethical marketing activities and practices that enhance collaborative marketing and subsequently innovate value chains and create sustainable business models in the sharing economy, as well as to the metaverse.
\end{abstract}

Keywords Trust $\cdot$ CBDC $\cdot$ Value creation

\section{Introduction}

Since the first-ever blockchain-based smart contractEthereum - has been widely used in the last few years, academic literature on blockchain technology (BT) has blossomed among business academics (Rossi et al., 2019). The research on BT is essential across all business school disciplines as this technology is expected to transform business processes (Mendling et al., 2018), operations (Filimonau $\&$ Naumova, 2020), and marketing (Kumar, 2018). BT is not just another technology innovation; it is a new form of institutional technology that could result in a radical change

Teck Ming Tan

teckming.tan@oulu.fi

Jari Salo

jari.salo@helsinki.fi

1 Department of Marketing, Management and International Business, Oulu Business School, University of Oulu, Pentti Kaiteran katu 1, 90570 Oulu, Finland

2 Department of Economics and Management, University of Helsinki, Latokartanonkaari 5, P.O. Box 27, 00014 Helsinki, Finland in organizations and subsequently drive them toward decentralized management (Tapscott \& Tapscott, 2017). Also, BT offers a new way to enforce agreements, and achieve cooperation and coordination between business partners (Lumineau et al., 2021). Importantly, BT is highly relevant (but not absolutely related) to the development of central bank digital currency (CBDC), and in July 2021, the European Central Bank (2021) launched a two-year digital euro project to investigate the design of users' preferences and technical advice. For these reasons, it is critical to research BT as companies may lose a competitive advantage in marketing if they overlook BT (Pawczuk et al., 2018). Companies may become obsolete if they are unable to cope with operational efficiency in the new markets (Fehrer et al., 2018).

The interplay between BT and ethical concern is a vital research domain as people could utilize BT to offer a new model of economic coordination and governance in the pursuit of each stakeholders' interests and well-being (Davidson et al., 2018). On the other hand, abusers can pervert BT and use it as a tool of surveillance (Areddy, 2021) and money laundering (Bryans, 2014). To date, limited attention has been given to providing guidelines on how ethical 
marketing ${ }^{1}$ research should be examined in the context of BT (Dierksmeier \& Seele, 2018, 2020). First, to the best of our knowledge, no study has provided a list of the key blockchain literature for the cross-disciplinary theories of business academics (see Table 1). Second, no study has provided a comprehensive discussion of the ethical marketing and stakeholder capitalism (Freeman et al., 2007) of the blockchain-based sharing economy, although previous studies have shown that BT involves multi-stakeholders and is related to the sharing economy (Avital, 2018; Bai \& Sarkis, 2020; Chong et al., 2019; Hawlitschek et al., 2018; Scott et al., 2017; Unalan \& Ozcan, 2020; Upadhyay, 2020; Veuger, 2018). Third, the ethical approach remains unexplored in many of the blockchain articles (Hyrynsalmi et al., 2020); most studies merely investigate how blockchain is related to data ethics compliance and the ethical issues of privacy concerns (Shim et al., 2019; Tang et al., 2020). Fourth, although a few studies have explained how blockchain is related to future research in marketing (Boukis, 2019; Cui et al., 2020; Rejeb et al., 2020), such exploratory discussions may not provide insights into how blockchainbased ethical marketing research is systematically conceptualized since they do not cover the three key foundations of marketing (Eckhardt et al., 2019): (a) institutions (i.e., consumers, firms, channels, and regulators), (b) processes (i.e., innovation, branding, customer experience, and value appropriation), and (c) value creation (i.e., value creation for consumers, value creation for firms, and value creation for society). For these reasons, our goal is to enrich and extend prior research by investigating BT in the context of ethical marketing and the sharing economy while underlining the stakeholder approach. This research is essential as it presents both the similarities between BT and the most popular sharing platforms (e.g., BlaBlaCar, Uber, Zipcar, Airbnb, LendingClub) and the shift of the logic of ethical marketing's beliefs and practices in the sharing economy.

To fill research gaps, we conducted a review of 163 research articles on blockchain by business academics. Review-based research is important as it can assist in assimilating existing blockchain knowledge and explicating focal areas that need significant scholarly attention (Hulland \& Houston, 2020). In this regard, our article synthesizes a set of fruitful fundamental views that aim to guide ethical marketing scholars when determining how the stakeholder approach (i.e., the descriptive, instrument, and normative approaches) to a blockchain-based sharing economy is positioned and how to better understand its implications in the context of stakeholder capitalism (Freeman et al., 2007).

\footnotetext{
${ }^{1}$ Ethical marketing refers to the process by which firms apply their moral standards to marketing decisions, behavior, and institutions (Javalgi \& La Toya, 2018).
}

This research is also relevant for practitioners who seek to comprehend how blockchain could serve as a strategic technology in the sharing economy. The contributions of this research are made by addressing four research questions: What publications form the key blockchain literature for the cross-disciplinary theories of business academics? How does BT result in a shift in ethical marketing logic in the sharing economy if we consider the three key foundations of marketing? How is BT related to the principles of stakeholder capitalism in the sharing economy if we consider the three key foundations of marketing? What are the future research directions for the stakeholder approach to ethical marketing in the blockchain-based sharing economy?

The remainder of the article is structured as follows. "Blockchain Research Among Business Academics" provides an overview of blockchain research. "The Background of the Study" describes the background of the study. "The Research Method" explicates the methodology adopted for the current review, followed by the selection of articles in "The Selection of Articles". "Document Co-Citation Clustering Analysis" presents the results of a co-citation analysis that identifies clusters of research areas in the blockchain literature. "Synthesisandthe Shift of Logic Required for Ethical Marketing in the Blockchain-Based Sharing Economy" presents a detailed discussion of the synthesis and the shift in logic found in ethical marketing in the blockchainbased sharing economy. "The Future Research Directions of the Stakeholder ApproachtoEthical Marketing in the Blockchain-Based Sharing Economy" offers future research avenues that are designed to push the boundaries of ethical marketing and the stakeholder approach regarding the blockchain-based sharing economy. "Conclusion" summarizes the shift of ethical marketing logic in the blockchainbased sharing economy.

\section{Blockchain Research Among Business Academics}

BT is considered as one of the technological innovations that have led to transformative marketing (Kumar, 2018). Further, BT plays an essential role in the sharing economy due to its efficient mechanism when used in peer-to-peer transactions (Eckhardt et al., 2019). The reason given is that, compared with the current state of the relational database, BT underlines five distinctive principles: a distributed network, peer-to-peer transmission, transparency with pseudonymity, the immutability of records, and computational logic (Catalini, 2017). With all these unique features, BT has been proven to create an 'Internet of trust' that guarantees trust in monetary transactions (e.g., Bitcoin transactions) and exchanges of information (e.g., an Ethereum smart contract), and directly lowers both the cost of verification and 


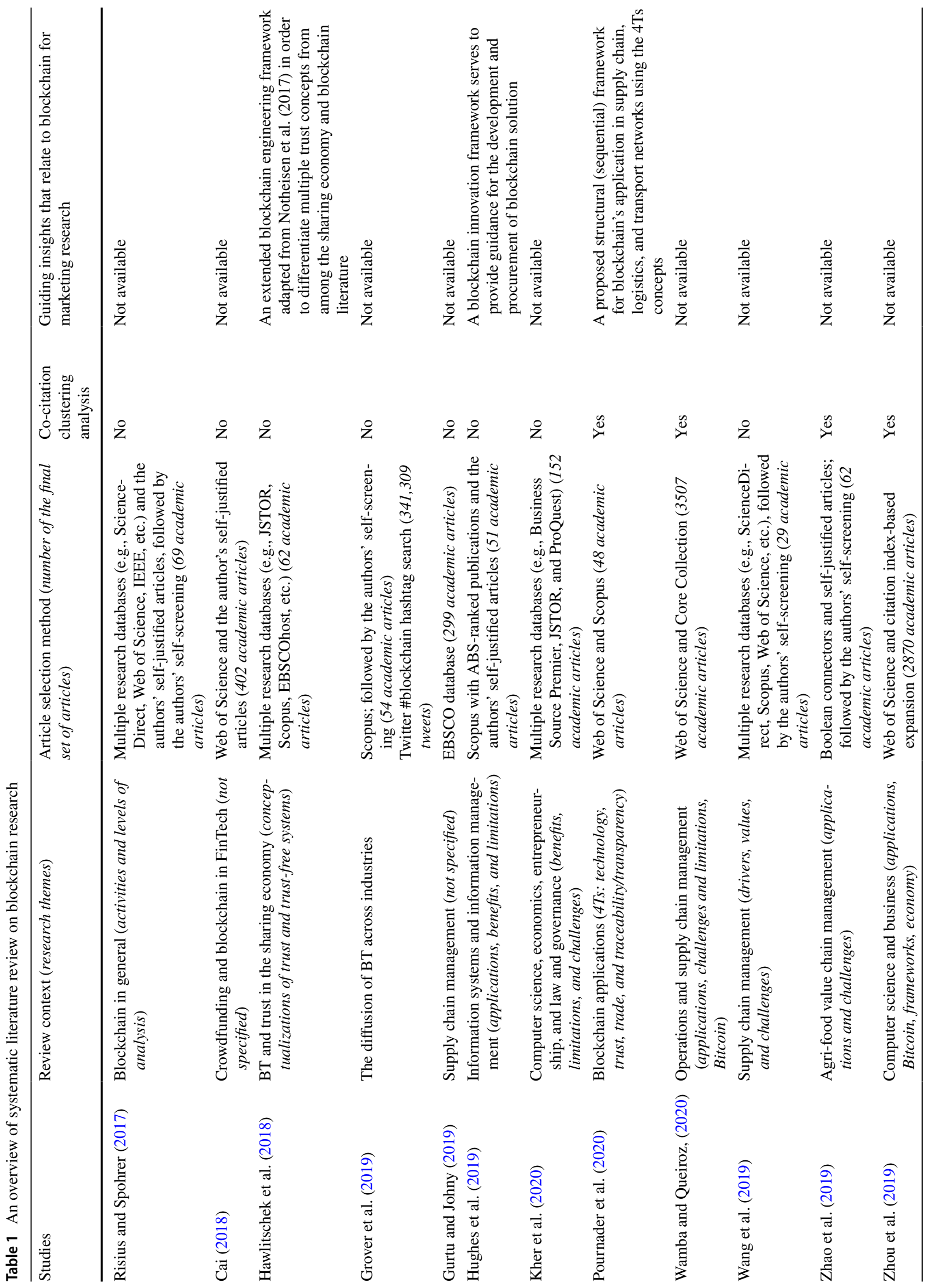




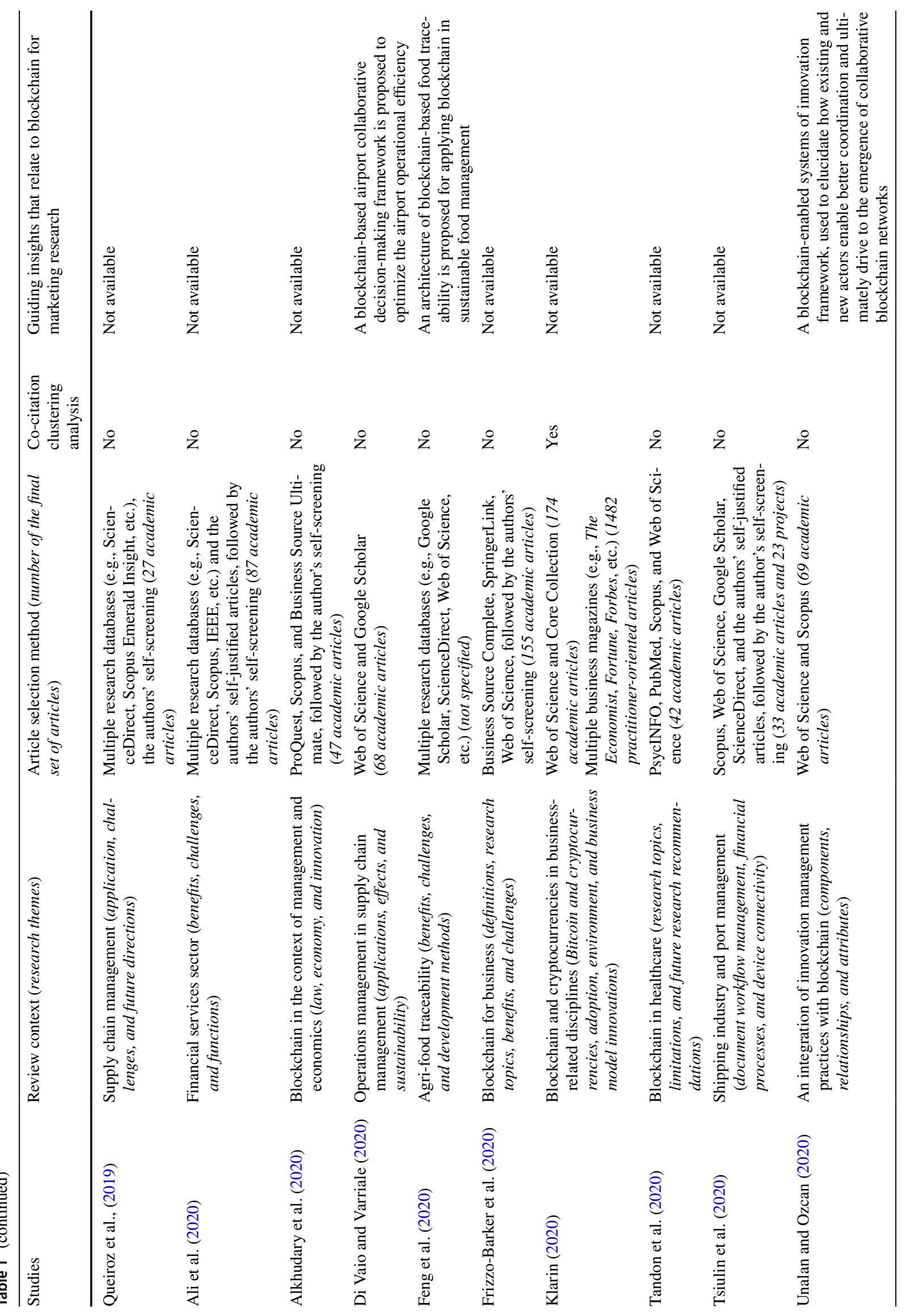


the cost of networking, which are traditionally covered by intermediaries in order to retain trust in economic transactions (Catalini \& Gans, 2020). Further, since the approval of the Token and Trustworthy Technology Service Providers Act (aka the Liechtenstein Blockchain Act or simply the Blockchain Act)—which came into force on January 1, 2020 — the development of blockchain's applications has moved beyond its application to financial assets and onto the notion of tokenizing any form of assets or rights, such as securities, rights to assets, rights to real estate, license rights, and rights of use (Tan \& Saraniemi, 2021). Hence, from the sharing economy perspective, BT is likely to provide consumers with a cost-effective experience by lowering costs, increasing fair competition, facilitating micropayments, and offering new types of decentralized applications and services (Harvey et al., 2018).

The business journals have crescively published research on blockchain reviews since 2017. As shown in Table 1, there are twenty-three studies from the 2021 journal guide of the Chartered Association of Business Schools (ABS) (previously known as the Association of Business Schools Journal Guide but recently rebranded as the Academic Journal Guide $[A J G])$ that are focused on systematic literature reviews. Risius and Spohrer (2017) found that blockchain research has focused on technological aspects and that frameworks vary across activities (i.e., design, creating features, measurement, capturing value, management, and organization) and levels of analysis (i.e., user, society, intermediary, platform, firm, and industry levels). Hawlitschek et al. (2018) highlighted that BT replaces the need to place trust in intermediaries by creating a "trust-free system"; however, the system is hardly able to build the trust mechanisms for the environment, infrastructure, and behavioral layers in the sharing economy. As for the blockchain innovation framework, Hughes et al. (2019) proposed the following five-step process for researchers and practitioners to help in the development and procurement of blockchain solutions: gaining knowledge, persuasion, making a decision, implementation, and confirmation. In terms of a blockchain application framework, Pournader et al. (2020) suggested that the technology itself is an independent variable that supports transparency and subsequently facilitates trade in the network, which is moderated by trust in the BT.

Researchers have demonstrated that BT enables existing and new actors to have better coordination and ultimately drives the emergence of collaborative business networks (Unalan \& Ozcan, 2020). In this regard, blockchain-based collaborative frameworks are proposed to accelerate the blockchain adoption process for organizational and environmental factors (Upadhyay, 2020) in order to optimize the operational efficiency (Di Vaio \& Varriale, 2020) and to increase sustainable food management (Feng et al., 2020). Thus, BT is suggested to have a positive impact on ethical 
marketing: on the environment component of sustainability (Upadhyay, 2020), on the social components (Feng et al., 2020), and on the economic component (Di Vaio \& Varriale, 2020). The remaining systematic review papers provide general findings across different industries, including findings on the applications and implementation stages (Grover et al., 2019; Queiroz et al., 2019; Wamba \& Queiroz, 2020; Zhou et al., 2019), benefits/values and challenges (Ali et al., 2020; Frizzo-Barker et al., 2020; Gurtu \& Johny, 2019; Kher et al. 2020; Queiroz et al., 2019; Tandon et al., 2020; Wamba \& Queiroz, 2020; Wang et al., 2019; Zhao et al., 2019), and research themes (Alkhudary et al., 2020; Cai, 2018; Frizzo-Barker et al., 2020; Klarin, 2020; Tandon et al., 2020; Tsiulin et al., 2020). Although the contributions of the existing review papers are undeniably important, none of the papers have provided insights into how blockchainbased marketing research is systematically conceptualized upon the three key foundations of marketing (Eckhardt et al., 2019): institutions, processes, and value creation. Further, as noticed in Table 1, there is no study that identifies the key blockchain literature for the cross-disciplinary theories of business academics.

\section{The Background of the Study}

\section{The Blockchain-Based Sharing Economy}

Following the notion of there being five essential characteristics (i.e., temporary access, the transfer of economic value, the expanded consumer role, crowdsourced supply, and technology-based matching platform mediation) of the sharing economy (proposed by Eckhardt et al., 2019), we argue that BT is related to the sharing economy as a previous study has demonstrated that BT can offer temporary access to a housing solution as an alternative to permanent ownership (Veuger, 2018). BT can entail economically motived access, and it serves as an engagement-facilitating technology platform, especially in supply chain management (Bai \& Sarkis, 2020; Di Vaio \& Varriale, 2020; Kamble et al., 2020). It also extends the consumer's role to become that of a prosumer-for example, in the energy industry (Nieto-Martin et al., 2019; Trbovich, 2019; Zhu et al., 2020)—whereby resources are accessed and verified by multi-stakeholders (i.e., crowdsourcing). As BT is characterized as a distributed ledger technology, the blockchain-based sharing economy can facilitate peer-to-peer exchange (e.g., Avital, 2018; Chong et al., 2019; Dai \& Vasarhelyi, 2017; Thakor, 2020). Thus, we advocated that BT should be nested within a sharing platform and it plays a decentralized role in the sharing economy (Hawlitschek et al., 2018), and such has been illustrated in the tourism industry (Rashideh, 2020), the logistics industry (Pournader et al., 2020), the financial industry
(Egelund-Müller et al., 2017), and the auditing industry (Dai et al., 2019).

Since the blockchain-based sharing economy is an emerging technological phenomenon that relates to sustainability and ethical issues (Casey \& Wong, 2017; Queiroz et al., 2019; Saberi et al., 2019), empirically rigorous work and theory-driven research on BT is needed in order to provide a deeper understanding of how an individual, a group, and organizational behavior vary in light of an openly available (albeit pseudonymous) sharing economy (Rossi et al., 2019). For instance, Lumineau et al. (2021) argued that BT is a governance mechanism as it facilitates cooperation (e.g., building a credible reputation system) and coordination (e.g., enabling transparency) between different organizations in the sharing economy, which depends upon tacit versus explicit transactions. However, this seminal work does not provide a discussion on the ethical or stakeholder theories of the blockchain-based sharing economy.

\section{The Stakeholder Approach to the Blockchain-Based Sharing Economy}

A blockchain ecosystem typically consists of the collaborations of multi-stakeholders that improve the efficiency and transparency of asset transfers (CB Insights, 2019). Apart from enhancing business efficiency and competitiveness, most blockchain solutions are being positioned or communicated to achieve common goals that relate to stakeholder well-being in the sharing economy (Scott et al., 2017; Unalan \& Ozcan, 2020; Upadhyay, 2020) and have been assessed from the perspective of stakeholder engagement (see, e.g., Pólvora et al., 2020). For instance, Maersk's TradeLens has been assessed for corporate citizenship, IBM's TrustChain for consumer well-being, the Dubai Blockchain Platform for the environmental sustainability, and Walmart's Food Trust for food transparency (Bajpai, 2019). Regrettably, due to the conflict of economic benefits and data-sharing governance, the above-mentioned use cases face challenges in onboarding more stakeholders in the ecosystem ( $\mathrm{Li}$ et al., 2021; Wight, 2018). One key reason is the lack of the notion of stakeholder capitalism (Freeman et al., 2007)—only a few parties benefit from long-term value creations, whereas most stakeholders are restricted by the barriers of BT adoption, including inter-organizational barriers, intra-organizational barriers, systems related barriers, and external barriers (Saberi et al., 2019). Thus, we argue that in the blockchainbased sharing economy, it is essential to assess how BT possibly fulfills the principles of stakeholder capitalism, as proposed by Freeman et al. (2007), including the principles of stakeholder cooperation, stakeholder engagement, stakeholder responsibility, complexity, continuous creation, and emergent competition. 


\section{Blockchain Ethics Research}

Recently, a few business scholars have explored the relationship between BT and ethics. Angel and McCabe (2015) described how a blockchain-based payment tool, such as cryptocurrency, can be used in an ethical or unethical manner. For this reason, consumers and business should consider the ethical implications while using cryptocurrency. Importantly, Malherbe et al. (2019) found that, due to dysfunctional monetary regimes and high transaction costs, the ethical commitment to relying on blockchain-based payment tools is considered unstable and impractical for daily use.

Mapping the micro, meso, and macro levels of business and society, Dierksmeier and Seele (2018) provided an assessment framework for assessing if the potential ethical impact of blockchain-based currency is morally beneficial, detrimental, or ambiguous. Subsequently, Dierksmeier and Seele (2020) suggested a three-dimensional moral assessment framework for blockchain-based business applications: ethically unfavorable, ethically favorable, and ethically ambivalent. To minimize ethically ambivalent applications (i.e., trustless trust, job platforms and the blurred line of public/private hands, and privacy versus secrecy), future research should emphasize how blockchain potentially contributes to the ethical and legal aspect of legislation, as well as to data deliberation (Dierksmeier \& Seele, 2020). To date, the ethical approach remains unexplored in many of the blockchain articles; most studies merely investigate how blockchain is related to data ethics compliance and the ethical issues of privacy concerns (Shim et al., 2019; Tang et al., 2020). Further, Hyrynsalmi et al. (2020) found no actual ethicality analysis or deeper understanding of moral philosophical discussions on ethical decision-making processes in the blockchain context.

\section{Marketing Ethics and Blockchain Research}

In terms of blockchain marketing, previous studies argue that some of the misleading concepts associated with BTsuch as disintermediation, data accountability, and traceability - have been exaggerated by the media as BT itself is a digital database infrastructure (Tan \& Saraniemi, 2021). The reasons given are that BT cannot replace all the marketing functions required for disintermediation (Tan \& Saraniemi, 2021), it faces inherent limitations when ensuring the reliability of information (Lemieux, 2016), and it cannot execute the recall of an unsafe food product, especially when the buyers use cash payment, and this results in the loss of traceability (Martindale et al., 2018).

According to Laczniak and Murphy (2006), marketing ethics are related to the systematic study of how marketing decisions, behavior, and institutions are incorporated with moral standards (the norms which we believe to be morally acceptable and morally unacceptable). There are two distinct approaches to marketing ethics: the term 'positive ethics' describes the changes of marketing-related moral standards that are based on empirical data, whereas the term 'normative ethics' provides justifications and reasons why a certain moral standard is being practiced and articulated (Laczniak \& Murphy, 2019). Interestingly, some of the core characteristics of BT (e.g., transparency, trustworthiness, and data integrity) are closely related to normative marketing ethics (Laczniak \& Murphy, 2019). To illustrate, Dierksmeier and Seele (2020) utilized normative frameworks-including utilitarianism, contractarianism, deontology, and virtue ethics-to conduct ethical analysis on the implications of blockchain ethics. Normative marketing ethics are essential as they imbue ethical marketing practices by establishing guidelines for decision makers to make more socially responsible judgments (Schlegelmilch \& Öberseder, 2010). Critically, although a blockchain ecosystem involves multistakeholders in the sharing economy (Lumineau et al., 2021), no study utilizes a stakeholder theory framework to initiate blockchain ethics research. For these reasons, this study aims to focus on stakeholder thinking in ethical marketing (Parmar et al., 2010) concerning blockchain research, rather than adding to the existing body of knowledge on blockchain applications and the ethics domain.

\section{The Research Method}

A wide range of techniques-such as citation analysis, author co-citation analysis, document co-citation analysis, co-word analysis, and textual analysis-are used in bibliographic research (Glänzel, 2015). To achieve the objectives of the current research, which serve to Research Question 1, "What publications form the key blockchain literature for the cross-disciplinary theories of business academics?", we only focus on document co-citation clustering analysis (Randhawa et al., 2016) that aimed to identify the key blockchain literature for cross-disciplinary theories (see Fig. 1). Then, we conceptualize ethical marketing in the blockchainbased sharing economy by illustrating how the identified blockchain capabilities and attributes challenge the three key foundations of marketing (Eckhardt et al., 2019) that delineates the principles of stakeholder capitalism (Freeman et al., 2007). Lastly, a future research agenda concerning a stakeholder approach to ethical marketing is presented.

\section{The Selection of Articles}

As BT is heavily related to computer science and information technology, we first identified keywords relevant to ethical marketing research that associate with blockchain 


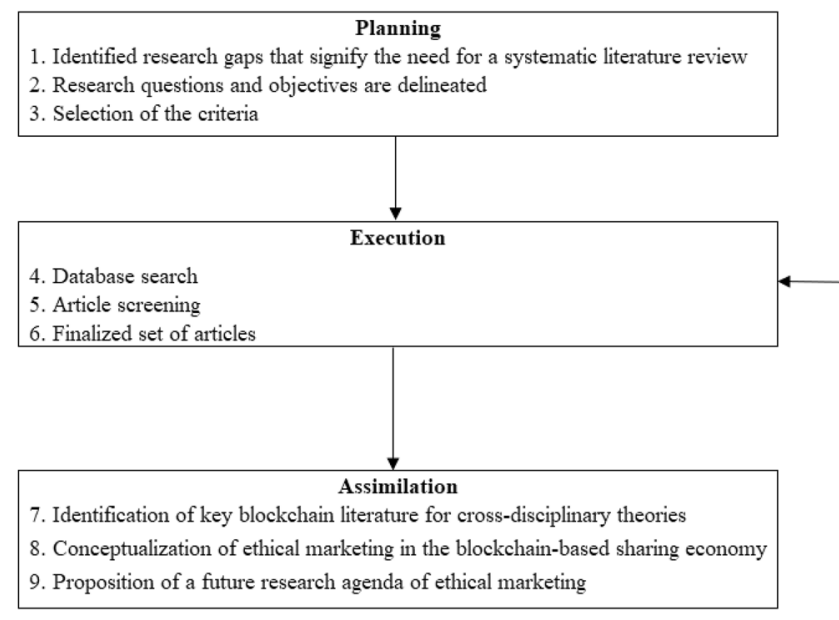

Fig. 1 The process and protocol for a review

for business use. We utilized keywords from the Journal of Business Ethics (JBE) for four reasons: First, the development and application of BT are associated with two extreme points: the benefits of ethical practices and unethical considerations (Tapscott \& Tapscott, 2016). Second, the JBE is a Financial Times-research ranked journal. Third, the $J B E$ publishes articles from various disciplinary perspectives related to business, such as marketing, management, strategy, organizational behavior, psychology, sociology, social entrepreneurship, accounting, economics, finance, governance, public policy, law, and technology. Forth, the $J B E$ covers a wide variety of business research keywords as it annually publishes approximately 400 articles in 24 issues.

The Web of Science (WoS) search engine was utilized as it focuses on unique scholarly journal articles (Bergman, 2012) and it allows users to customize their search according to article title, abstract, and keywords, rather than basing their search on an entire article's content. Importantly, WoS features Keyword Plus ${ }^{\circledR}$ - a unique list of keywords harvested from the titles of the cited articles; this keyword feature is critical as it effectively assists researchers in including more relevant articles during the literature review (Zhang et al., 2016). We used WoS to search through JBE articles published between January 2010 and June 2020, which provided us with 3739 results and 20,149 keywords. We manually ranked the keywords using an Excel pivot table and a few rounds of the synchronizing process. As shown in Table 2, 42 marketing ethics-related keywords that had frequencies over 20 were identified, and we combined those keywords with a blockchain term (e.g., 'blockchain' or 'ethics') using the WoS database's search engine to search through article titles, abstracts, author keywords, and WoS Keyword Plus, resulting in identifying 1,868 unique articles.
Next, we conducted an article screening process using the $2021 \mathrm{ABS} / \mathrm{AJG}$ journal rankings as it is a reputable journal ranking system that is used to assess the quality of business and management research work (Walker et al., 2019). In this regard, this system assists us in effectively selecting recognizable blockchain-related research articles. A final set of 163 selected articles (publication years: from 2015 to June 2020) were identified with the following composition of ranked journals: ABS4 $*=5(3 \%), \mathrm{ABS} 4=5(3 \%)$, $\mathrm{ABS} 3=40(24 \%), \mathrm{ABS} 2=79(49 \%)$, and $\mathrm{ABS} 1=34(21 \%)$. The final set of 163 selected articles consist of four articles from the Association for Information Systems senior scholars' basket of journals ${ }^{2}$ (see Online Appendix A).

To further confirm that we included all the blockchain articles concerning marketing and business research, we manually looked for (i.e., searched for 'blockchain') highimpact articles in eight marketing journals, as suggested by Khamitov et al. (2020), including searching in the Journal of Marketing, Journal of Marketing Research, Journal of Consumer Research, Journal of Consumer Psychology, Marketing Science, Journal of the Academy of Marketing Science, Journal of Retailing, and the Journal of Service Research. Following a further search of ten Financial Timesresearch ranked journals (i.e., the Academy of Management

\footnotetext{
2 The Association for Information Systems senior scholars' basket of journals includes the European Journal of Information Systems, Information Systems Journal, Information Systems Research, Journal of the Association for Information Systems, Journal of Information Technology, Journal of Management Information Systems, Journal of Strategic Information Systems, and MIS Quarterly. An important note is that we also conducted a screening process for all blockchainrelated articles from these eight journals; this analysis further confirmed that only four articles are related to the blockchain-in-ethics context (article indices: 12, 28, 55, and 149).
} 
Table 2 The keywords used for the search of the blockchain and ethical marketing articles

\begin{tabular}{|c|c|c|}
\hline Keywords & $\begin{array}{l}\text { Frequency found in } 3739 \mathrm{JBE} \\
\text { articles }\end{array}$ & $\begin{array}{l}\text { Frequency found in the final set of } 163 \text { selected } \\
\text { articles (i.e., 'blockchain' and 'each of the listed } \\
\text { keywords') }\end{array}$ \\
\hline 1. Corporate social responsibility (CSR) & 690 & 1 \\
\hline 2. Ethic(s) & 514 & 11 \\
\hline 3. Ethical & 253 & 7 \\
\hline 4. Stakeholder & 240 & 29 \\
\hline 5. Corporate governance & 180 & 3 \\
\hline 6. Sustainability & 179 & 29 \\
\hline 7. Institutional & 61 & 10 \\
\hline 8. Legitimacy & 61 & 2 \\
\hline 9. Trust & 61 & 66 \\
\hline 10. Corruption & 50 & 3 \\
\hline 11. Corporate responsibility & 47 & 1 \\
\hline 12. Corporate social performance & 41 & - \\
\hline 13. Unethical & 34 & 1 \\
\hline 14. Social responsibility & 32 & 1 \\
\hline 15. Accountability & 31 & 11 \\
\hline 16. Fraud & 31 & 10 \\
\hline 17. Fairness & 30 & 1 \\
\hline 18. Moral & 30 & 6 \\
\hline 19. Regulation & 30 & 25 \\
\hline 20. Fair trade & 30 & - \\
\hline 21. Justice & 30 & - \\
\hline 22. Responsibility & 29 & 6 \\
\hline 23. Spirituality & 29 & - \\
\hline 24. Agency theory & 28 & 1 \\
\hline 25. Corporate philanthropy & 28 & - \\
\hline 26. Organizational citizenship behavior & 28 & - \\
\hline 27. Human rights & 27 & - \\
\hline 28. Moral disengagement & 27 & - \\
\hline 29. Sustainable development & 26 & 7 \\
\hline 30. Corporate reputation & 26 & - \\
\hline 31. Stakeholder management & 26 & - \\
\hline 32. Whistleblowing & 26 & - \\
\hline 33. Socially responsible investment & 25 & - \\
\hline 34. Virtue & 25 & 1 \\
\hline 35. Virtue & 23 & 1 \\
\hline 36. Sustainability reporting & 23 & - \\
\hline 37. Organizational justice & 22 & - \\
\hline 38. Institution(s) & 21 & 26 \\
\hline 39. Transformational & 21 & 2 \\
\hline 40. Transformative & 21 & 5 \\
\hline 41. Abusive & 21 & - \\
\hline 42. Responsible leadership & 21 & - \\
\hline
\end{tabular}

A keyword search of Web of Science includes title, abstract, author keywords, and Web of Science Keyword Plus® (i.e., a unique list of keywords harvested from the titles of the cited articles); JBE Journal of Business Ethics

Each selected article contains at least one result from the combination (e.g., 'blockchain' and 'corporate social responsibility or CSR') of the blockchain and ethical marketing keywords

Counted as one frequency whenever a keyword appears multiple times on an article's title, abstract, author keywords, and Web of Science Keyword Plus ${ }^{\circledR}$ 
Journal, Academy of Management Review, MIS Quarterly, Journal of Management, Journal of Operations Management, Operations Research, Organization Science, Journal of International Business Studies, Journal of Business Ethics, and Strategic Management Journal) over the last ten years. The results were consistent, indicating that blockchain research is relatively young and in a growth phase among the marketing and business ethics disciplines. ${ }^{3}$

\section{Document Co-citation Clustering Analysis}

The objective of this research is to identify the key blockchain literature for the cross-disciplinary theories of business academics. To achieve this objective, we used document co-citation analysis. To identify the most impactful seminal research within the research field (Small, 1973), we manually counted the number of hits for each of the 163 articles' reference lists. ${ }^{4}$ A total of 9,358 reference lists were found; however, we reduced our list to 84 highly cited articles with at least seven hits. Upon checking the first-round list, we excluded 16 articles as 9 articles were conference proceedings, 6 were working papers, and 1 was a GitHub article. This reduced our list to 68 highly cited articles.

The ABI/INFORMS database was used to collect co-citation frequencies for each pair of articles (Harzing \& Alakangas, 2016), resulting in a co-citation matrix. The diagonal values of the matrix are treated as missing values in the analysis (White \& Griffith, 1981). This process reduced the list by 15 articles as these articles had a co-citation frequency of 0 , resulting in a final list of 53 highly cited articles. A $53 \times 53$ co-citation matrix was then converted into a matrix of proximity values (i.e., Pearson correlation coefficients). The absolute values in the proximity matrix in this study were as high as 1 (the diagonal value) and as low as 0 (showing no correlation between a pair of articles). The proximity matrix indicated the degree to which two articles were cited together and the sub-domains were identified using cluster

\footnotetext{
3 Importantly, two articles from the Journal of Marketing (Cui et al., 2020; Morewedge et al. 2020), one from the Strategic Management Journal (Momtaz 2020), one from Organization Science (Lumineau et al., 2021), and finally, one MIS Quarterly (Ilk et al., 2021) were published after our data collection-these were not included in the review or in the co-citation clustering analysis.

${ }^{4}$ We conducted an extensive review of each of the 163 selected articles. Our analysis found that previous research has been prioritized on (a) blockchain applications across industries, followed by (b) the potential of BT, and (c) blockchain in finance and accounting information systems. An important note is that most of the discussions are related to a general level of business content, which indicates that the research on blockchain ethics is not sufficiently researched by marketing scholars. We have provided a summary of the 163 selected articles as Appendix B. By using the articles, we synthesize BT's relationship to ethical marketing perspectives in Sects. 7 and 8.
}

analysis (Dagnino et al., 2015). The number of clusters is determined using hierarchical cluster analysis (Hair et al., 2010). To create groups of articles representing different research sub-domains, $k$-means clustering was used (Dillon \& Goldstein, 1984). Moreover, an ANOVA for final cluster centers was also conducted for comparison. The final results indicated that the three-cluster solution provided better discrimination and statistical significance $(p<0.001)$ for clusters (Dillon \& Goldstein, 1984).

\section{Results}

As shown in Table 3, our findings reveal three blockchain clusters: (a) 'blockchain capabilities' refer to the abilities of BT to perform a particular business activity by leveraging the applications of BT, (b) 'blockchain attributes' are the core values that define the overall nature of the BT; the seven attributes of BT serve as the key set of considerations for the business need, ${ }^{5}$ and (c) the 'underlying economic theories of blockchain' are the theories that are found in the literature of blockchain for business.

\section{Blockchain Capabilities (Cluster 1)}

Cluster 1 contains 12 articles that explore the capabilities of BT. Three sub-clusters are identified: strategic technology, trustworthy digital records management, and operational transformation.

'Strategic technology' refers to the use of the BT to identify long-term business goals as it offers a new strategic model of economic coordination between exchange parties. Previous research has found blockchain's strategic roles in improving financial inclusion and remittances, strengthening cybersecurity, protecting privacy and sensitive information, issuing cryptocurrency, eliminating institutional intermediaries, developing a trustworthy technology, increasing the political influence of software engineers in the business environment, facilitating global commerce, creating selfsovereign identity, and accelerating distributed collaborative organizations (Kshetri, 2017b; Larios-Hernández, 2017; Scott et al., 2017; Ying et al., 2018).

In terms of 'trustworthy digital records management,' Lemieux (2016) demonstrated that, with a precondition of secured architecture and IT infrastructure management, blockchain-based record management is a solution

\footnotetext{
5 We use 'attributes' as this term can be used to refer to the qualities or features regarded as the inherent part of BT. We did not use the term 'characteristic,' which refers to distinguishing features or qualities. An important note is that some of the blockchain attributes (e.g., strategic value, and digitalization and sustainability's convergence in the ecosystem) are as well evidenced in other types of technology, such as the Internet of things and AI.
} 
Table 3 Identified clusters and topics

\begin{tabular}{|c|c|c|}
\hline Cluster & Sub-cluster & Topic \\
\hline \multirow[t]{3}{*}{ Blockchain capabilities } & Strategic technology & $\begin{array}{l}\text { Financial inclusion, cybersecurity, privacy and sensitive information, } \\
\text { cryptocurrency, intermediaries, trustworthy technology, political influ- } \\
\text { ence of software engineer, global commerce, self-sovereign identity, } \\
\text { and distributed collaborative organizations }\end{array}$ \\
\hline & Trustworthy digital records management & The integrity and reliability of information \\
\hline & Operational transformation & $\begin{array}{l}\text { Business resilience, peer-to-peer payment, foreign exchange platforms, } \\
\text { digital rights/identity management, energy microgrid, smart contracts, } \\
\text { insurance, drone navigation, business process innovation, and collabo- } \\
\text { rative business models }\end{array}$ \\
\hline \multirow[t]{7}{*}{ Blockchain attributes } & Consensus mechanism & $\begin{array}{l}\text { Technical network consensus is required to verify and publish transac- } \\
\text { tions }\end{array}$ \\
\hline & Digital transformation in asset management & The commercialization of both tangible and intangible assets \\
\hline & Programmable properties & $\begin{array}{l}\text { Self-verification, self-executing contracts, a shared distributed ledger/ } \\
\text { database, and automated clearing and reconciliations }\end{array}$ \\
\hline & Blockchain governance & $\begin{array}{l}\text { Decision rights, accountability, incentives alignment, trustworthiness, } \\
\text { tradable assets, ownership management, the market, and network } \\
\text { governance }\end{array}$ \\
\hline & Strategic value & $\begin{array}{l}\text { Transactional cost, risk reduction, supply chain provenance, transparency } \\
\text { with pseudonymity, real-time data analytics, resource integration, a } \\
\text { trust-free business environment, and the tokenization of assets }\end{array}$ \\
\hline & $\begin{array}{l}\text { Digitalization and sustainability's conver- } \\
\text { gence in the ecosystem }\end{array}$ & Economic, social, and environmental sustainability in the ecosystem \\
\hline & Value perception & The production of value, recording value, and the actualization of value \\
\hline $\begin{array}{l}\text { Underlying economic } \\
\text { theories of block- } \\
\text { chain }\end{array}$ & N/A & $\begin{array}{l}\text { The economic institutions of capitalism, transaction cost theory, trust } \\
\text { theory, information asymmetry theory, stakeholder theory, and the dif- } \\
\text { fusion of innovations theory }\end{array}$ \\
\hline
\end{tabular}

for addressing information integrity (e.g., access control, user verification, and audit trails); however, blockchain has an inherent limitation when ensuring the reliability of information as it does not guarantee how the information has originated, who creates the record, and how the information is created during the process of record creation.

'Operational transformation' is related to how BT provides support for a range of collaboration functionalities in advanced collaborative software systems. Researchers have suggested that blockchain enhances business resilience, which is expected to improve risk management systems-making them more reactive-with self-executing digital contracts, multilayer protection with improved data security that is capable of detecting both tangible and invisible risks, and the shared visibility and traceability of transactions and information flow (Min, 2019; Wang et al., 2019). Further, the integration of BT and the Internet of things (IoT) is expected to create more businessbased peer-to-peer payment mechanisms, foreign exchange platforms, digital rights or identity management, an energy microgrid, smart contracts involving IoT devices, insurance networks for IoT assets, investment in IoT devices, the sharing of the airspace market for drone navigation, innovation in business process modeling and manufacturing processes, and collaborative business models (Huckle et al., 2016; Mougayar, 2016; Pan et al., 2020; Reyna et al., 2018; Xu et al., 2018).

\section{Blockchain Attributes (Cluster 2)}

Cluster 2 contains 33 articles that identify the attributes of blockchain in the sharing economy. Seven sub-clusters are further analyzed and categorized: consensus mechanisms, digital transformation in asset management, programmable properties, blockchain governance, strategic values, digitalization and sustainability's convergence in the ecosystem, and value perception.

A 'consensus mechanism' is "a method of authenticating and validating a value or transaction on a blockchain or a distributed ledger without the need to trust or rely on a central authority" (Seibold \& Samman, 2016, p. 1). Since blockchain is a social technology (Yeoh, 2017), various consensus mechanisms are used to achieve network consensus in order to verify and publish transactions, such as proof of work, proof of stake, proof of existence, proof of burn, proof of activity, proof of capacity, deposit-based Byzantine agreement, and rotation schemes (Lu \& Xu, 2017; Sikorski et al., 2017; Zheng et al., 2018).

Generally, 'asset management' is defined as the process of developing, operating, maintaining, and selling assets. 
Nowiński and Kozma (2017) suggested that firms could adopt BT in transforming both tangible and intangible asset management as part of the business model in order to commercialize their underlying assets, distinguished by strategic components (i.e., strategy, resources, and networks), customer and market components (i.e., customers, the market offering, and revenue), and value creation components (i.e., manufacturing, procurement, and financial components).

'Programmable properties' refers to the self-executing attribute of BT (e.g., the digital contract) that automatically performs the terms and conditions of digital-asset transfers in a blockchain (Wang et al., 2019). Researchers have indicated four properties that facilitate more efficient digital-asset transfers: self-verification, self-executing contracts, a shared distributed ledger/database, and automated client account clearing and reconciliations (Dai \& Vasarhelyi, 2017; Fanning \& Centers, 2016; Kiviat, 2015; Mainelli \& Smith, 2016; Narayanan et al., 2016; Ølnes et al., 2017; Peters \& Panayi, 2016).

'Blockchain governance' is defined as "the means of achieving the direction, control, and coordination of stakeholders within the context of a given blockchain project to which they jointly contribute" (Pelt et al., 2021, p. 21). Researchers have identified eight dimensions that enhance the existing knowledge of a governance framework in the sharing economy: decision rights (from centralized to decentralized rights), accountability (from legal institutions to the technical approach), incentives' alignment (from intermediaries to developers/users/token holders), trustworthiness (from inter-organizational trust to trustworthy technology), tradable assets (from tangible and intangible assets to tokenized assets), ownership management (which focuses on the origin of ownership), the market (which involves more autonomous actors [e.g., automated machines], the IoT, and decentralized autonomous organizations), and network governance (moving from business-oriented approaches to multi-stakeholders or open-source approaches) (Beck et al., 2018; Böhme et al., 2015; Christidis \& Devetsikiotis, 2016; Crosby et al., 2016; Kewell et al., 2017; Tapscott \& Tapscott, 2016; Underwood, 2016; Yli-Huumo et al., 2016).

'Strategic values' are created when firms extract greater value from the adoption of BT in achieving sustainable competitive advantages. Researchers have demonstrated that BT underlies eight core strategic values, including lower transactional costs, risk reduction, supply chain provenance, transparency with pseudonymity, real-time data analytics, resource integration, the notion of a trust-free business environment, and the tokenization of assets (Francisco \& Swanson, 2018; Hawlitschek et al., 2018; Iansiti \& Lakhani, 2017; Kim \& Laskowski, 2018; Kshetri, 2018; Tapscott \& Tapscott, 2017; Treiblemaier, 2018; Yermack, 2017).

With regard to 'digitalization and sustainability's convergence in the ecosystem,' researchers (Casey \& Wong,
2017; Queiroz et al., 2019; Saberi et al., 2019) have found that the current applications of BT more effectively manage economic sustainability (e.g., they improve responsiveness, reduce lead time, and reduce transaction costs) and environmental sustainability (e.g., they reduce greenhouse gas emissions, water usage, and energy consumption) than they manage social sustainability (e.g., improvements in equity, labor practices, decent work, and human rights). The reason given is that the social metrics of sustainability are not objectively measured, and the survey data of social performance are not collected automatically via blockchain applications. With respect to the trade-off of adopting BT, significant resources are allocated to the development and governance of the BT and the privacy issue, as well as to the potential legal risk involved in cross-border data sharing (Casey \& Wong, 2017; Queiroz et al., 2019; Saberi et al., 2019).

In terms of 'value perception,' researchers summarize three dimensions that provide a better understanding of a BT use case (Pazaitis et al., 2017) and the amount raised from initial coin offerings (Fisch, 2019): the production of value (i.e., source code quality, use value, and production for sharing), the recording of value (i.e., a technical white paper and decentralized consensus), and the actualization of value (i.e., the amount of token supply, the Ethereum standard, and perceived social benefits).

\section{The Underlying Economic Theories of Blockchain (Cluster 3)}

Cluster 3 contains 8 articles that explain the underlying economic theories of blockchain, including the economic institutions of capitalism (Davidson et al., 2018; Williamson, 1985), transaction cost theory (Coase, 1937; Williamson, 1979), trust theory (Davidson et al., 2018), information asymmetry theory (Akerlof, 1970), stakeholder theory (Akerlof, 1970; Davidson et al., 2018; Williamson, 1985), and the diffusion of innovations theory (Hevner et al., 2004; Mollick, 2014; Rogers, 1995).

Blockchain is considered an institutional technology rather than a general-purpose technology as it is a distributed ledger technology that possibly excludes the existing sets of institutions-markets, hierarchies, relational contracting (Williamson, 1985) — and offers a new model of economic coordination and governance, including ledger entry and private keys for property rights, public keys and decentralized networks for exchange mechanisms, cryptocurrencies/CBDC for fiat currencies, code for law, and initial coin offerings for alternative finance (Davidson et al., 2018). In this sense, the economics of blockchain emphasize the efficiency of lowered transaction costs (Coase, 1937; Williamson, 1979) via effective institutional innovations (e.g., smart contracts) that minimize the problems of information asymmetries (Akerlof, 1970). 


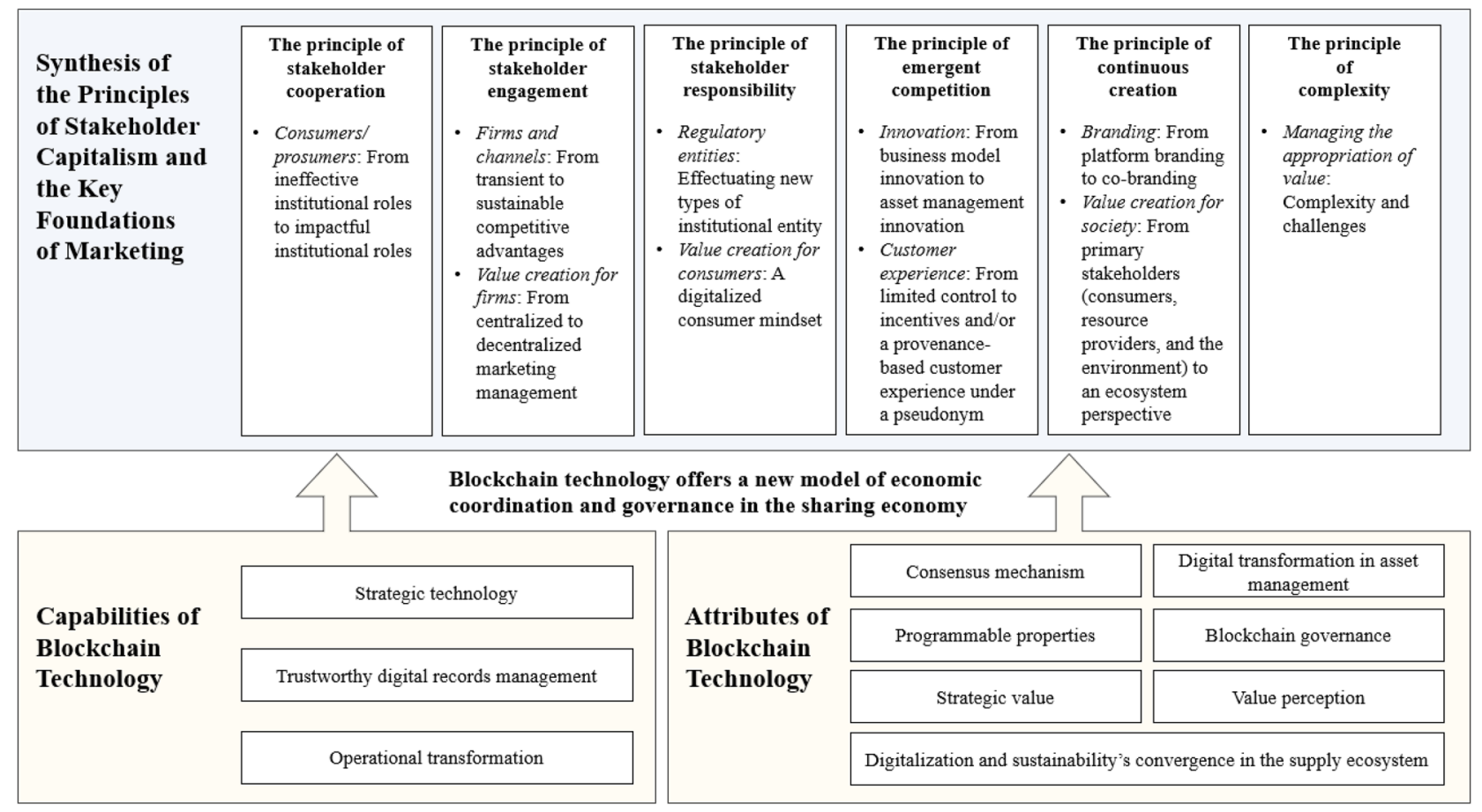

Fig. 2 The ethical marketing in the blockchain-based sharing economy

Thus, in blockchain economics, a shift of trust from traditionally trusted coordinators (e.g., bankers and government agencies) to BT is incurred as it is an authentication and verification technology that enables the exchange of value and the transfer of ownership in an otherwise trustless environment (Davidson et al., 2018). An important note is that blockchain is also a social technology as it is a set of social protocols (i.e., it is a consensus mechanism) built upon a blockchain infrastructure and a platform for the exchange of property rights, information, and interests across different stakeholders in the sharing economy (Akerlof, 1970; Davidson et al., 2018; Williamson, 1985), such as customers, BT providers, sellers, suppliers, farmers, government agencies, and financial institutions. As such, the diffusion of innovations theory (Hevner et al., 2004; Mollick, 2014; Rogers, 1995) is adopted to investigate how the rapid spread of BT is transforming different industries and social activities across stakeholders.

\section{Synthesis and the Shift of Logic Required for Ethical Marketing in the Blockchain-Based Sharing Economy}

To answer Research Question 2, "How does BT result in a shift in ethical marketing logic in the sharing economy if we consider the three key foundations of marketing?" and Research Question 3, "How is BT related to the principles of stakeholder capitalism in the sharing economy if we consider the three key foundations of marketing?" we utilized the key foundations of marketing proposed by Eckhardt et al. (2019) in order to provide guiding insights about the shifts of logic required in the blockchain-based sharing economy compared with the existing sharing platforms (e.g., BlaBlaCar, Uber, Zipcar, Airbnb, LendingClub). As presented in Fig. 2, our discussions are illustrated using the elements of the identified blockchain capabilities and attributes highlighted in italics in the body text, and they delineate how the shift of each logic is related to the principles of stakeholder capitalism (Freeman et al., 2007).

\section{Consumers/Prosumers: From Ineffective Institutional Roles to Impactful Institutional Roles}

As highlighted by Eckhardt et al. (2019), consumers take on expanded roles and become prosumers in the sharing economy. For instance, Alex may be an Uber driver (i.e., a producer) on weekdays and an Uber customer (i.e., a consumer) during weekends. In this regard, the prosumer may take on institutional roles in the sharing economy, such as roles related to communication, promotion, and quality control (Eckhardt et al., 2019). However, we agree with Schor (2016) that prosumers hold an ineffective institutional role in the existing sharing platforms since they do not have autonomous power and are completely controlled by the sharing platform brands. Unlike the Ethereum 
prosumers in the blockchain-based sharing economy, some of them may be a trader, a miner, a validator, or a developer (Kiviat, 2015). Thus, Ethereum prosumers hold impactful institutional roles as they significantly contribute to the blockchain consensus mechanism and blockchain governance (Zheng et al., 2018); their influences will gradually shape the operational transformation of a particular blockchain platform/brand (Pazaitis et al., 2017). In this context, consumers/prosumers focus on the social nature of value creation by making voluntary agreements (i.e., self-executing contracts) with other exchange parties-the principle of stakeholder cooperation (Freeman et al., 2007). For these reasons, we suggest that consumers/prosumers in the blockchain-based sharing economybe they holder, trader, validator, or developer-shall have a higher level of self-identity that is congruent with BT; they shall be more willing to post and share blockchain/ crypto-related posts online; and they shall preferably be addressed as a 'blockchain expert,' 'blockchain enthusiast,' 'blockchain developer,' or 'crypto evangelist.' As such, consumers/prosumers not only hold moral values and duties for themselves but also hold the existing value and expectations of the blockchain/crypto communities.

\section{Firms and Channels: From Transient to Sustainable Competitive Advantages}

We argue that the existing sharing platforms form an excellent example of transient competitive advantages that focus on the practice of taking up new strategic initiatives based on short-lived advantages (McGrath, 2013). The reason given is that the existing sharing platforms gain short-term profits from their innovative business model without directly investing resources into their products and employees; they heavily rely on crowdsourcing and/or prosumers (i.e., on cost saving), and subsequently, they cannot control the quality of the resource providers and fail to ensure the consistency of servicescapes (Eckhardt et al., 2019). In contrast, firms and channels that wish to adopt BT are required to invest amount of resources since this technology will replace the existing digital records management systems in order to facilitate resource sharing with multi-stakeholders in the ecosystem (Lemieux, 2016). Thus, a concept of sustainable competitive advantages that focuses on stakeholders' value is emphasized to clarify both how BT could serve as a strategic technology and to what extent the firms and channels could benefit from the strategic values in the blockchainbased sharing economy. That is, firms and channels have to focus on how to sustain value creation among the exchange parties by engaging them in the ecosystem for the purpose of satisfying the needs of multi-stakeholders-this follows the principle of stakeholder engagement (Freeman et al., 2007).

\section{Regulatory Entities: Effectuating New Types of Institutional Entity (Logic Unchanged)}

Similar to the existing sharing platforms in the sharing economy, regulator entities need to draft a new set of legal frameworks that specifically serve governing blockchain capabilities and attributes. For instance, the approval of the Liechtenstein Blockchain Act, which came into force on January 1,2020 , has introduced a new list of blockchain service providers. Drawing on intermediary functions (Alderson \& Martin, 1965) and middleman theory (Krakovsky, 2015), Tan \& Saraniemi (2021) found that the descriptive roles of the blockchain service providers that are stated in the Liechtenstein Blockchain Act involve the providers performing marketing functions since BT itself does not have the capacity to match potential sellers and buyers. Therefore, in line with the work of Eckhardt et al. (2019), we believe that any proposed blockchain legal framework would result in new types of institutional entity for blockchain governance and that such an effect will offer both opportunities and challenges for ethical marketing scholars. For instance, a new type of institutional entity is a new type of legal custodian that is responsible for ensuring a link between the online and the offline world, where a physical, real asset continues to exist once the asset is tokenized. Further, we expect that firms would create more special-purpose entities to alleviate their ethical responsibilities - subsidiaries created by a parent firm to isolate financial and ethical risk-and to secure them from bankruptcy while adopting BT. In addition, central banks have been researching the potential for CBDC and certain countries have utilized a digital banking currency as a tool of surveillance, which has resulted in an ethical argument around the topic. As such, regulatory entities must develop a set of legal frameworks that will create and sustain more value in the blockchain projects so that exchange parties are willing to accept and be accountable for their responsibilities-this follows the principle of stakeholder responsibility (Freeman et al., 2007).

\section{Innovation: From Business Model Innovation to Asset Management Innovation}

As noted by Eckhardt et al. (2019), the majority of the existing sharing platforms have ignored product innovation (i.e., there is a lack of product differentiation) as they heavily rely on business model innovation. On the other hand, digital transformation in asset management and the use of the programmable properties of BT are proposed in the blockchainbased sharing economy (Nowiński \& Kozma, 2017). Ahluwalia et al. (2020) suggested that firms could utilize BT to commercialize both tangible and intangible assets digitally by tokenizing their assets. 'Asset tokenization' refers to the process of converting the ownership rights to a particular 
asset into a digital token in a blockchain for self-execution, such as the rights to real estate (e.g., land and houses), rights to assets (e.g., diamonds and paintings), or license rights (e.g., music rights) (Tan \& Saraniemi, 2021). For instance, a firm could leverage the strategic value of BT by publicly trading some of their digital tokens that relate to a unit of a property investment asset (Wolfson, 2018). In terms of resource sharing in a permissioned blockchain, Di Vaio and Varriale (2020) found that the granularity of information is a feature of dynamic asset management. That is, data owners could provide low data access to others for a specific purpose for a particular period, which would enhance the flexibility of data sharing and data monetization in the blockchainbased sharing economy. Therefore, we expect that the relationship between asset tokenization and asset management innovation should have a direct impact on firms' subsequent ethical marketing activities. In this sense, the innovation process is leading toward a relatively free society that allows stakeholders to have different options in their asset management for competitiveness - this follows the principle of emergent competition (Freeman et al., 2007)—which means that investment in assets (e.g., real estate and cutting-edge technology) is an emergent property rather than a necessary investment assumption for capitalism.

\section{Branding: From Platform Branding to Co-branding}

Using the existing sharing platforms that form the research context (e.g., Uber and Airbnb), previous research has found that temporarily accessible brands (vs. brands that are owned by consumers) have resulted in a lower level of brand attachment and those brands are less likely to serve as a means of reflecting a consumer's self-concept (Bardhi \& Eckhardt, 2012). Further, Eckhardt et al. (2019) stated that sharing platform brands may gain more benefits, as well as loyalty, from consumers since they heavily rely on the sharing platform itself rather than on the brands that are accessible on the platform. Contradictory to this, we argue that in the blockchain-based sharing economy, co-branding between firms is relatively essential as BT is a strategic technology that requires a consortium to start gathering a team of players who have a common end goal in mind in order to solve a problem (Ying et al., 2018), this can be seen in blockchain's capability to improve financial inclusion (Larios-Hernández, 2017), strengthen cybersecurity (Kshetri, 2017a), and facilitate cross-border payment and commerce (Fanning \& Centers, 2016). Thus, the consortium generally consists of multistakeholders looking for digitalization and sustainability's convergence in the ecosystem for stakeholder well-being (Tiscini et al., 2020). Further, it is critical to emphasize the value perception of a blockchain project; Fisch (2019) found that the initial coin offerings associated with a wellknown blockchain brand (i.e., Ethereum) and a high-quality white paper (i.e., recording value) were more likely to gain attention and funding from investors. Thus, the co-branding strategy between the brands and blockchain firms could be leveraged for ethical marketing, including authentic brand storytelling, blockchain-enabled loyalty programs, traceable online advertising, reduced counterfeit consumption, brand transparency, and trust of brands in online marketplaces (Boukis, 2019). In this regard, brand managers have to collaborate with other stakeholders in the ecosystem to create new sources of brand values - this follows the principle of continuous creation (Freeman et al., 2007).

\section{Managing the Customer Experience: From Limited Control to Incentives and/or a Provenance-Based Customer Experience Under a Pseudonym}

As highlighted previously, the existing sharing platforms heavily rely on business model innovation by crowdsourcing and/or recruiting prosumers as the resource providers. Thus, brands that are accessible on the existing sharing platforms are unable to manage customer experiences across all touchpoints along the journey, and subsequently, those brands only have limited control over the quality of the user's experience (Eckhardt et al., 2019). However, we propose that in the context of permissionless BT, the nature of the customer journey in the sharing economy may shift, becoming an incentive experience (Harvey et al., 2018), which means that consumers are prepared to share their pseudonymous personal information with a brand in exchange for a micropayment made on a decentralized application. A micropayment is considered an incentive and it is an e-commerce token or alternate cryptocurrency that can be used in exchange for products or services that are available online (Christidis \& Devetsikiotis, 2016; Crosby et al., 2016). Thus, brands that are accessible on the BT decentralized platforms can utilize programmable self-executing contracts to provide more personalized experiences to incentivize customers according to their pseudonymous profile (Tshering \& Gao, 2020). Apart from this, a non-fungible token-a unit of data on a blockchain that represents a unique, immutable, and collectible digital item-could be utilized to track the history of and receive a loyalty fee for the valuable items that are sold to each pseudonymous buyer in the marketplace.

As for permissioned BT, especially when used in the application of supply chain management, blockchain enables a provenance-based customer experience due to its immutable and trustable digital record management that is shared among stakeholders in the ecosystem (Kshetri, 2018). For example, Walmart engages with farmers, logistic companies, intermediaries, and competitors while implementing a data provenance-based project using IBM permissioned blockchain-aiming to ensure food freshness and sustainability, to eliminate the chance for food fraud, and to minimize food 
waste (Corkery \& Popper, 2018)—which has enabled firms to constantly keep track of the known and pseudonymous information about the food value chain. Thus, in both permissionless and permissioned BT, managers have to practice the principle of emergent competition (Freeman et al., 2007) by viewing the process of managing the customer experience (i.e., due to pseudonymous) as an emergent property rather than a data-driven strategy for capitalism. The main reason given is that in the blockchain-based sharing economy, customers move toward a self-sovereign identity approach that focuses on how they can control their identity and privacy in a decentralized ecosystem (Berg et al., 2018).

\section{Managing the Appropriation of Value: Complexity and Challenges (Logic Unchanged)}

In line with the notion of Eckhardt et al. (2019), in the blockchain-based sharing economy, we expect the appropriation of value to be even more complex and challenging for blockchain firms as they have to compete against the existing sharing platforms, prosumers as resource providers, traditional firms, and also other blockchain firms. An important note is that blockchain governance plays a critical role in the process of how a blockchain firm appropriates strategic value from the marketplace. For instance, the blockchain market involves more autonomous actors (e.g., machines, the IoT, and decentralized autonomous organizations; Christidis \& Devetsikiotis, 2016; Davidson et al., 2018), and the network governance shifts from being business oriented to using multi-stakeholders or open-source approaches (Unalan \& Ozcan, 2020). Thus, blockchain firms may need to compete against a decentralized autonomous organization, and at the same time, a collaborative business model that fulfills multistakeholders is essential in order to generate substantial revenue through alliances in the blockchain-based sharing economy (i.e., operational transformation). In this sense, the principle of complexity (Freeman et al., 2007) shall be practiced as the appropriation of value is complex in the blockchain-based sharing economy; managers need to evaluate and balance between diverse values and points of view from different forms of stakeholders, including the human being, machine, and decentralized autonomous organizations.

\section{Value Creation for Consumers: A Digitalized Consumer Mindset}

The online platforms' capability to match algorithms serves as a key factor that accelerates the demand and supply of shared resources in the sharing economy (Sutherland \& Jarrahi, 2018). Thus, access-based consumption or temporarily accessible/shared resources are heavily associated with the consumer's activities in the online context (Bardhi \& Eckhardt, 2012); we use the term 'online' since consumers nowadays are laboriously engaged with online activities, such as online shopping, online networking, online entertainment, online communication, and online work at home. Nonetheless, we argue that such a record of activities on online platforms do not consist of a consumer's right of ownership of the online properties. For instance, a historical and summary record of a dedicated Uber driver or a good Uber customer might only be viewed on the Uber sharing platform and not be accessible on another, existing sharing platform (e.g., Lyft) or vice versa; it is needless to mention the possibility of consumers themselves owning, controlling, sharing, or monetizing their online data. Thus, there is a lack of selfsovereign identity solutions in the current sharing economy, which means that consumers/prosumers nowadays have no ownership and little control over how their valuable personal information is stored, used, and accessed online. For this reason, most highly skilled resource providers use the existing sharing platforms opportunistically by identifying potential clients and then continuing to transact with them outside of the platforms (Zhou et al., 2019).

In contrast, we suggest that individuals form a 'digitalized' consumer mindset when they are engaged with a decentralized blockchain identity platform. The reason given is that a decentralized identity allows consumers to have the ability to control and be responsible for their personal information online (Tapscott \& Tapscott, 2016), which means that consumers will have the absolute right of ownership of their online records in a blockchain ecosystem (i.e., they have self-sovereign identity; Underwood, 2016). As such, consumers should develop a strong congruence between their online and offline profiles as the decentralized identity can be cryptographically shared with other parties once they grant permission for it to be shared. At this stage, the consumer mindset shall be digitalized, and he or she should be more ethical in his or her online behavior and accountable for it as an immutable and authenticated record of his or her historical profile that can be retrieved effortlessly from a blockchain database with the granted permission (i.e., he or she should practice trustworthy digital records management). In this regard, the blockchain-based sharing economy may decrease consumer risk and promote different types of authentic experiences among ethical consumers. That is, values are created, traded, and sustained as consumers are willing to accept responsibility for the consequences of their online actions-this follows the principle of stakeholder responsibility (Freeman et al., 2007).

\section{Value Creation for Firms: From Centralized to Decentralized Marketing Management}

One key difference is that BT (vs. the existing sharing platforms) can transform firms' operations in the blockchainbased sharing economy. For instance, the decentralized 
feature of BT that integrates with other stakeholders' shared databases to create capacity-managed and time-responsive solutions (Min et al., 2019) requires firms to adopt BT into their business operations by joining the existing blockchain consortium (Peters \& Panayi, 2016) in order to fully utilize the value chain in the business networks and optimize the overall efficiency of the business, maximize financial resources, and minimize waste for sustainability. For instance, optimizing the value chain has significantly reduced the cost of verification in the context of the blockchain database (Catalini \& Gans, 2020). Thus, we argue that, in the blockchain-based sharing economy, firms need to shift their logic from centralized to decentralized marketing management as the elements of digitalization and sustainability's convergence in the ecosystem require a distributed and ethical philosophy that is delegated away from a central, authoritative location or group. In this regard, firms have to practice the principles of stakeholder engagement (Freeman et al., 2007) as decentralized marketing management requires the strong engagement of multi-stakeholders for value creation; the multi-stakeholders consist of primary stakeholders (e.g., farmers, suppliers, customers, employees, and financiers) and secondary stakeholders (regulators, technology providers, trade associations, and NGOs).

\section{Value Creation for Society: From Primary Stakeholders (Consumers, Resource Providers, and the Environment) to an Ecosystem Perspective}

As positioned by Eckhardt et al. (2019), the current state of the sharing economy entails economic motivation that renders temporary access to underutilized resources between consumers and resource providers. Thus, most of the existing discussions on societal value concern primary stakeholders, for instance, there have been discussions on the impacts on consumers and resource providers (Aknin et al., 2019; Calvey, 2016; Semuels, 2018) and on the environmental impacts of consumer consumption in the sharing economy (Hellwig et al., 2015; Le Vine et al., 2014; Martin \& Susan, 2011; Perren \& Kozinets, 2018; Schor, 2016; Sisson, 2018). In contrast, in the context of a blockchain-based sharing economy, societal value is related to the convergence of $B T$ and sustainability in the supply ecosystem (Bai \& Sarkis, 2020). The ecosystem view allows focusing on resource integrations between "any number of actors for the well-being of each individual actor and for the system as a whole" (Jonas et al., 2018, p. 402), which could be viewed as a recursive process connected with stakeholders' common goals (Vargo $\&$ Lusch, 2017). To achieve societal values today, nonhuman actors, such as autonomous machines (Storbacka, 2019; Storbacka et al., 2016), are often involved in the ecosystems as relevant contributors with regard to engagement in the ecosystem. On the other hand, technologies have been acknowledged as important engagement platforms in the related literature (Breidbach \& Brodie, 2017; Ramaswamy \& Ozcan, 2016), enabling stakeholder engagement and contributing to societal value. Thus, the role of BT in an ecosystem has two facets, either that of an actor or enabler. This notion is important when identifying the societal and ethical values gained in the blockchain-based sharing economy from the ecosystem perspective, which underlines the principle of continuous creation (Freeman et al., 2007) that emphasizes how BT as an institutional technology that motivates stakeholders continuously creates new sources of value for society.

\section{The Future Research Directions of the Stakeholder Approach to Ethical Marketing in the Blockchain-Based Sharing Economy}

To answer Research Question 4, "What are the future research directions for the stakeholder approach to ethical marketing in the blockchain-based sharing economy?" a broader perspective of the stakeholder approach is utilized as stakeholder theory is found in the underlying economic theories of blockchain and it is a theory of business ethics that addresses morals and values in the market economy (Donaldson \& Preston, 1995). Further, stakeholder theory is related to the blockchain ecosystem as BT is a collaborative technology and the benefits are only realized through engaging with other stakeholders in the sharing economy (Scott et al., 2017; Unalan \& Ozcan, 2020; Upadhyay, 2020).

Parmar et al. (2010) stated that stakeholder thinking in ethical marketing consists of three theoretical approaches to considering stakeholder claims. The descriptive approach refers to research that makes factual claims or shreds of evidence about what practitioners and brands actually do in ethical marketing, such as their specific characteristics and behavior; this approach describes when and why decision makers are ethically responsible for certain stakeholders or deny their ethical responsibility for certain stakeholders. The instrument approach relates to research that focuses on the outcomes of specific managerial ethical behavior-such as focusing on the specific links between cause (e.g., transparency, integrity, and the decentralized perspectives of ethical marketing) and effect (e.g., brand performance, reputation, competitive advantages, and value creation) - in detail. The normative approach refers to research that provides justifications for why a certain moral standard is being practiced and articulated, such as philosophical guidelines for operation and management that relate to ethical marketing. This approach focuses on the interest of all the stakeholders in the ecosystem and not just those of investors; it also emphasizes 
the theory of fairness (e.g., justice and equity), rather than status and power.

In the following section, we illustrate a list of future research questions (FRQs) based on the shift of logic required for ethical marketing in the blockchain-based sharing economy. As presented in Table 4, we highlight the relevancy (i.e., - for a neutral connection, + for a moderate connection, and ++ for a strong connection) of each FRQ concerning the descriptive, instrument, normative approaches of stakeholder theory. In this regard, each FRQ is not specifically viewed from a particular stakeholder approach; it serves as a theory-driven direction with which researchers can position and justify their scholarly works. A critical note is that a neutral connection indicates that the FRQ does not provide clear support to the respective stakeholder approach. For this reason, a strong justification is needed to embark on research related to a FRQ with a neutral connection to the stakeholder approach.

\section{Institutions}

\section{Consumers}

As consumers increasingly expand their institutional roles and become prosumers in the blockchain-based sharing economy, marketing scholars could engage in research that attempts to more deeply understand the various ethical (vs. unethical) roles and processes that are interlinked to each other when prosumers shape their identity and the surrounding society at large. A number of central issues need to be addressed in future. First, how does a blockchain-based sharing economy with engaged prosumers change consumer culture and ethics? Second, how do the ethical (vs. unethical) roles and consumption processes change when consumers shift from consumer to prosumer and back? Third, since prosumers will have a higher level of institutional roles when they become influential developers or validators, how does a consumer or prosumer identity alter when the person is engaged in different stages of identity self-congruence? Fourth, what kind of institutional roles are played by the consumers/prosumers in the blockchain-based sharing economy, and how could these institutional roles potentially be misused or abused? Fifth, to what extent does BT change the way consumers/prosumers consider their ethical decisionmaking in a peer-to-peer file sharing situation (Bateman et al., 2013)?

\section{Firms and Channels}

Firms and channels in the blockchain-based sharing economy fundamentally change how marketing assets can be managed and how channels of distribution and manufacturing are sustainably operated. A number of key issues need to be addressed. First, how are asset transparency and increased trust influencing the moral philosophies of marketing asset management for sustainable competitive advantages? Second, as trust is facilitated at least partly by the blockchain-based sharing economy, how is trust firstly built and subsequently leveraged across the ecosystem? Further, how does trust among firms and channels alter when the adoption of the blockchain-based sharing economy increases? Third, as distribution and manufacturing operations are already effective in many countries (i.e., the tasks and processes are divided into multiple phases that are operated by several different stakeholders), how can ethical marketing scholars effectively access empirical blockchain data about a manufacturing chain or distribution chain for sustainable competitive advantages? Fourth, what kind of moral philosophies (e.g., moral idealism and moral relativism) provide best practices during the collaborative marketing process that are required to develop a sustainable business model that is shared among the stakeholders in the ecosystem (Hyman \& Kostyk, 2019)?

\section{Regulatory Entities}

As for regulator entities, their interest in, for example, public policy regarding the blockchain-based sharing economy mainly lies in the intersection of how firms conduct their business by utilizing BT and, at the same time, how they take care of their government- and society-related responsibilities while serving their customers/prosumers. The key issue asked here is: How will the blockchain-based sharing economy alter the current public policy procedures that different government and governmental institutions have put into place for the welfare or well-being of the general public? In the same vein, a second aspect to be considered is how firms can adapt to the changes that the blockchain-based sharing economy will have on the public policy regime that surrounds their business operations, especially for those multinational firms that exist in different countries and thus encounter difficulty in attaining the degree of morality set by international marketing ethics. A third aspect to ponder is: How, in the long run, can a blockchain-based sharing economy alter the ways firms, consumers/prosumers, and governmental institutions jointly engage in more transparent, trustful, and ethical policymaking? A fourth issue is how can the creation of special-purpose entities that ensure the legal system is not being misused in the blockchain-based sharing economy be monitored? Lastly, how can a technical and legal framework for CBDC be designed that serves to maintain citizens' privacy and to enhance the payment experience, rather than using digital banking currency as a tool of surveillance? 
Table 4 Stakeholder approaches to ethical marketing in the blockchain-based sharing economy

Future research questions (FRQs)

The shift of ethical marketing logic in the blockchain-based sharing economy

Stakeholder approach

Consumers/prosumers: from ineffective institutional roles to impactful institutional roles

a. How does a blockchain-based sharing economy with engaged prosumers change consumer culture and + ethics?

b. How do the ethical (vs. unethical) roles and consumption processes change when consumers shift from consumer to prosumer and back?

c. How does a consumer or prosumer identity alter when the person is engaged in different stages of identity self-congruence?

d. What kind of institutional roles are played by the consumers/prosumers in the blockchain-based shar- $\quad+$ ing economy, and how could these institutional roles potentially be misused or abused?

e. To what extent does BT change the way consumers/prosumers consider their ethical decision-making + in a peer-to-peer file sharing situation?

Firms and channels: from transient to sustainable competitive advantages

a. How are asset transparency and increased trust influencing the moral philosophies of marketing asset management for sustainable competitive advantages?

b. How is trust firstly built and subsequently leveraged across the ecosystem?

c. How does trust among firms and channels alter when the adoption of the blockchain-based sharing economy increases?

d. How can ethical marketing scholars effectively access empirical blockchain data about a manufacturing chain or distribution chain for sustainable competitive advantages?

e. What kind of moral philosophies (e.g., moral idealism and moral relativism) provide best practices during the collaborative marketing process that are required to develop a sustainable business model that is shared among the stakeholders in the ecosystem?

Regulators entities: effectuating new types of institutional entities

a. How will the blockchain-based sharing economy alter the current public policy procedures that different government and governmental institutions have put into place for the welfare or well-being of the general public?

b. How firms can adapt to the changes that the blockchain-based sharing economy will have on the public policy regime that surrounds their business operations, especially for those multinational firms that exist in different countries and thus encounter difficulty in attaining the degree of morality set by international marketing ethics?

c. How, in the long run, can a blockchain-based sharing economy alter the ways firms, consumers/ prosumers, and governmental institutions jointly engage in more transparent, trustful, and ethical policymaking?

d. How can the creation of special-purpose entities that ensure the legal system is not being misused in the blockchain-based sharing economy be monitored? e. How can a technical and legal framework for CBDC be designed that serves to maintain citizens'
privacy and to enhance the payment experience, rather than using digital banking currency as a tool of surveillance?

Innovation: from business model innovation to asset management innovation

a. What is the ethical role of the firms in innovating their assent management when the blockchain-based + sharing economy increases the number of collaborative options with other firms, the network of firms, consumers, and prosumers alike?

b. How is the shift from consumers to prosumers intensifying and altering their lead-user position and + engagement in asset management innovation (i.e., asset tokenization) for stakeholder well-being?

c. What kind of moral influences does the blockchain-based sharing economy have on the differentia innovation types (product, process, technology, and open and closed business model innovation) and offering types (radical-incremental offerings)?

Branding: from platform branding to co-branding

a. How the blockchain-based sharing economy is changing how we attach to ethical brands, how we consume them, and how we build loyal, versus negative, relationships with them?

b. Does ethical production among brands has direct impacts on consumers' ethical consumption? And how could both positive and negatives impacts be captured in the co-branding process?

c. How does ethical manufacturing shape the moral practices among brand managers?

$\overline{\text { Descriptive Instrument Normative }}$

$++$

$+$

$++$

$+$

$+$

$+$

$+$

$+$

$+$

$$
\text { - }
$$

$+$

$+$

$$
++
$$

$+$

$++$

$$
++
$$

$+$

$++$

$+$

$+$

$+$

$++$

$++$

$++$

$++$

$+$

$++$

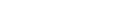

++
+
+
+

$+$

$++$

$+$

$+$ 
Table 4 (continued)

Future research questions (FRQs)

Stakeholder approach

The shift of ethical marketing logic in the blockchain-based sharing economy

Descriptive Instrument Normative

d. How do the firms throughout the value chain engage in co-branding and ethical marketing activities for a mutual-benefit relationship?

e. If and when a blockchain-based sharing economy creates options for brand managers to increase both ++ origin and verification possibilities, are brand managers jumping in or hesitating in their brand alliance decision-making? Why do they behave as they do?

f. How does BT shift private-label brand-related research from the consumer-centric, retailer-centric, and manufacturer-centric perspectives?

Managing the customer experience: from limited control to incentives and/or a provenance-based customer experience

a. What kind of ethical values might influence (or not influence) managing customer experience as a whole?

b. How could marketing scholars increase understanding of consumer/prosumer reactions to the lost privacy or possible data management challenges that might occur?

c. How to ethically handle the transition from a traditional sharing economy to a blockchain-based sharing economy while creating omnichannel customer experiences?

d. How could customers' planned behavior possibly shape a future experience of their ethical attitudes and judgments?

e. To what extent can firms utilize the existing metrics, and in what situation should they develop a new set of metrics without compromising the corporate ethical values?

f. To what extent and how could customers change their beliefs about the ethicalness of an ad and the efficacy of an ad in the blockchain-based sharing economy?

Managing the appropriation of value: complexity and challenges

a. Is there a first-mover advantage? Or a second-mover advantage in the blockchain-based sharing economy?

b. How to provide a better understanding about the competitive actions and reactions regarding marketing asset use and specific marketing activities (e.g., how ethical marketing and competition are changing amidst a blockchain-based sharing economy)?

c. How does BT affect ethical practices of internal marketing activities and their influences on value appropriation?

Value creation for consumers: a digitalized consumer mindset

a. How consumer ethical consumption is seen from the value creation point of view when information is more transparent and how the available heuristics for ethical decision-making increase in quantity and quality?

b. What kinds of products/services are ethically (vs. unethically) offered in the blockchain-based sharing + economy?

c. What kinds of products/services are consumed and why? How is a new type of ethical value percep- $\quad++$ tion formed in the blockchain-based sharing economy?

d. Is the sharing practice within the blockchain economy going to increase among green consumers, and + if so, in what industries or communities of consumption?

e. What kind of additional values will be co-created among consumers/prosumers and what are the tradeoffs of ethical judgments (e.g., sharing privacy while monetizing personal data) during the process?

Value creation for firms: from centralized to decentralized marketing management

a. How are customers responding to transparency? Do they reward firms for transparency or punish them + for it?

b. Do faster payments result in ever-increasing reverse logistics problems?

c. Does information about the origin of components (e.g., the raw materials of vegan food) badly influence the business and consumer ethical choices, as well the firm's efforts toward green marketing?

d. What kind of moral philosophies would affect firms so that they would rely on a decentralized market- ing effort rather than centralized marketing and vice versa?

Value creation for society: from primary stakeholders to an ecosystem perspective

a. Is less sometimes more and better for society?

b. Can we factor in welfare or happiness in customer lifetime value calculations, or should we move to societal-impact-over-lifetime calculations?

\begin{tabular}{|c|c|c|}
\hline+ & ++ & + \\
\hline++ & + & - \\
\hline- & ++ & ++ \\
\hline+ & + & + \\
\hline+ & ++ & + \\
\hline++ & + & + \\
\hline+ & ++ & - \\
\hline- & ++ & + \\
\hline+ & + & ++ \\
\hline+ & ++ & + \\
\hline+ & ++ & + \\
\hline++ & + & + \\
\hline+ & + & + \\
\hline++ & + & + \\
\hline+ & ++ & + \\
\hline+ & ++ & - \\
\hline+ & ++ & + \\
\hline- & + & ++ \\
\hline+ & + & - \\
\hline+ & ++ & - \\
\hline
\end{tabular}


Table 4 (continued)

\begin{tabular}{|c|c|c|c|}
\hline \multirow{2}{*}{$\begin{array}{l}\text { Future research questions (FRQs) } \\
\text { The shift of ethical marketing logic in the blockchain-based sharing economy }\end{array}$} & \multicolumn{3}{|c|}{ Stakeholder approach } \\
\hline & Descriptive & Instrument & Normative \\
\hline $\begin{array}{l}\text { c. How and when can we nudge customers, firms, and governments to utilize BT in the sharing economy } \\
\text { for the greater good? }\end{array}$ & + & ++ & ++ \\
\hline $\begin{array}{l}\text { d. Where can marketing collect the data within a blockchain ecosystem, and how can that data be inte- } \\
\text { grated throughout a value chain involving multistakeholder well-being? }\end{array}$ & + & ++ & + \\
\hline
\end{tabular}

The relevancy of each FRQ concerning stakeholder approach: - for a neutral connection; + for a moderate connection; ++ for a strong connection. A neutral connection indicates that the FRQ does not provide clear support to the respective stakeholder approach. For this reason, a strong justification is needed to embark on research related to a FRQ with a neutral connection to the stakeholder approach

\section{The Marketing Process}

\section{Innovation}

The first sub-process, namely asset management innovation, is fostered as transparency and trust are increased. A number of central issues need to be addressed in future. First, marketing scholars could focus on the question, 'What is the ethical role of the firms in innovating their assent management when the blockchain-based sharing economy increases the number of collaborative options with other firms, the network of firms, consumers, and prosumers alike?' Second, how is the shift from consumers to prosumers intensifying and altering their lead-user position and engagement in asset management innovation (i.e., asset tokenization) for stakeholder well-being? Third, what kind of moral influences does the blockchain-based sharing economy have on the differential innovation types (product, process, technology, and open and closed business model innovation) and offering types (radical-incremental offerings)?

\section{Branding}

The second sub-process, branding, is benefitting from the transparency of origin and verification possibilities. The first issue that marketing scholars could envisage is how the blockchain-based sharing economy is changing how we attach to ethical brands, how we consume them, and how we build loyal, versus negative, relationships with them? Second, as the blockchain-based sharing economy enables better verification and origin management of the brands and their traditional or digital production process, the key issue to be addressed is whether ethical production among brands has direct impacts on consumers' ethical consumption? And how could both positive and negatives impacts be captured in the co-branding process? How does ethical manufacturing shape the moral practices among brand managers? Third, how do the firms throughout the value chain engage in co-branding and ethical marketing activities for a mutual-benefit relationship? Fourth, from a more managerial perspective, if and when a blockchain-based sharing economy creates options for brand managers to increase both origin and verification possibilities, are brand managers jumping in or hesitating in their brand alliance decision-making? Why do they behave as they do? Fifth, since BT is a strategic technology, how does BT shift private-label brand-related research from the consumer-centric, retailer-centric, and manufacturer-centric perspectives (Hyman et al., 2010)?

\section{Customer Experience}

The third sub-process, customer experience, can be seen as a composite of the interactions and the outcomes that the consumer/prosumer has with the ethical firm over a lifetime. Critically, more research is needed as the blockchain-based sharing economy allows for incentives and/or a provenancebased customer experience. A number of key issues need to be addressed. First, marketing research is needed to understand if trust in the firm, the brand, and the industry is altering with regard to managing the customer experience, and if so, why it is doing so. What kind of ethical values might influence (or not influence) managing customer experience as a whole? Second, as transparency is increased, privacy and data management issues are most likely brought to the fore. Hence, marketing scholars could increase understanding of consumer/prosumer reactions to the lost privacy or possible data management challenges that might occur. Third, and considering the other side of the same coin, marketing research could provide marketing management guidelines for firms on how to ethically handle the transition from a traditional sharing economy to a blockchain-based sharing economy while creating omnichannel customer experiences. Fourth, since consumers have an option to receive an incentive for their upcoming personalized experience, how could such planned behavior possibly shape a future experience of their ethical attitudes and judgments? Fifth, in terms of managing provenance-based customer experience, to what extent can firms utilize the existing metrics, and in what situation should they develop a new set of metrics without compromising the corporate ethical values? Six, in terms of advertising ethics, since BT relates to data provenance that enhances data transparency, to what extent and how could 
customers change their beliefs about the ethicalness of an ad and the efficacy of an ad (Hyman et al., 1994) in the blockchain-based sharing economy?

\section{Value Appropriation}

The fourth sub-process, value appropriation, is tightly linked to the competitors who are also engaged in the blockchainbased sharing economy. A number of key issues need to be addressed. First, marketing scholars could focus their research efforts on the order of the blockchain-based sharing economy entries of different firms in different industries and build models explaining entry strategy influences, for example, Tobin's $q$. Is there a first-mover advantage? Or a second-mover advantage? Second, research activity could be directed toward understanding the competitive actions and reactions regarding marketing asset use and specific marketing activities (e.g., how ethical marketing and competition are changing amidst a blockchain-based sharing economy). Third, one can ponder how within-firm value appropriation alters due to the blockchain-based sharing economy. This would include exploring the ethical practices of internal marketing activities and their influences on value appropriation.

\section{Value Creation Outcomes}

\section{Value for Consumers}

As for consumers, the blockchain-based sharing economy provides a trustful source of information that is used in daily prosuming and consumption. First, the antecedents of value creation that are linked to information providers need to be understood clearly as consumers form a digitalized mindset in the blockchain-based sharing economy. For marketing scholars, interesting questions to tackle are how consumer ethical consumption is seen from the value creation point of view when information is more transparent and how the available heuristics for ethical decision-making increase in quantity and quality. Second, the types of firm that excel in the blockchain-based sharing economy will also influence the availability of different types of digital services with different value creation potential for the green consumer. Key issues for future marketing scholars are then, what kinds of products/services are ethically (vs. unethically) offered in the blockchain-based sharing economy? What kinds of products/ services are consumed and why? How is a new type of ethical value perception formed in the blockchain-based sharing economy? Linked to the above is also the question of how effective payments can be facilitated by the BT (Angel \& McCabe, 2015). Is the sharing practice within the blockchain economy going to increase among green consumers, and if so, in what industries or communities of consumption? Since
BT allows consumers to control their right of ownership of online properties (i.e., it allows them to create self-sovereign identity), what kind of additional values will be co-created among consumers/prosumers and what are the tradeoffs of ethical judgments (e.g., sharing privacy while monetizing personal data) during the process?

\section{Value for Firms}

The outcomes for firms in the blockchain-based sharing economy are plentiful. The increased transparency of marketing chains and consumption chains accelerates the growth of environmentally friendly and ethically sound firms. Payments are received earlier or immediately, which helps in cash flow management. As tracing the origin of components and materials becomes easier, their ethical consumption and presumption is facilitated. Firms with 'nothing to hide' in their marketing efforts will shape markets. For marketing research, these firms open new avenues for future research on decentralizing marketing management. The questions to be addressed are linked to the activities of decentralized marketing management that are conducted within the firm to increase the value creation that is in turn linked to the blockchain-based sharing economy. First, how are customers responding to transparency? Do they reward firms for transparency or punish them for it? Second, do faster payments result in ever-increasing reverse logistics problems? Third, does information about the origin of components (e.g., the raw materials of vegan food) badly influence the business and consumer ethical choices, as well the firm's efforts toward green marketing? Fourth, what kind of moral philosophies would affect firms so that they would rely on a decentralized marketing effort rather than centralized marketing and vice versa?

\section{Value for Society}

As for society at large, more value is created in a more streamlined fashion (e.g., more taxes, less child labor, fewer frauds, a cashless economy, equal work rights). The blockchain-based sharing economy creates digital goods and services with less pollution. An offering is digital in many instances. Besides, the environmental considerations, such as carbon footprints, also influence the happiness of green consumers, and the number of consumers might increase as one becomes aware of the source of food, the components of the mobile phone, or labor conditions. For marketing scholars, several interesting questions emerge. First, is less sometimes more and better for society? Second, can we factor in welfare or happiness in customer lifetime value calculations, or should we move to societal-impact-over-lifetime calculations? Third, how and when can we nudge customers, firms, and governments to utilize BT in the sharing economy for 
the greater good? Fourth, from where can marketing collect the data within a blockchain ecosystem, and how can that data be integrated throughout a value chain involving multistakeholders' well-being?

\section{Conclusion}

This study synthesizes and proposes the shift of ethical marketing logic in the blockchain-based sharing economy by comparing it with the commonly referred to sharing platforms. This synthesis includes the shifts (1) from consumers/ prosumers' ineffective roles to impactful institutional roles, (2) from a firm's transient competitive advantage to sustainable competitive advantages, (3) from business model innovation to asset management innovation, (4) from platform branding to co-branding among stakeholders, (5) from limited control to managing incentives and/or a provenancebased customer experience under a pseudonym, (6) from an online context to a digitalized consumer mindset, (7) from firms' centralized marketing management to decentralized marketing management, and (8) from a primary stakeholder (consumers, resource providers, and the environment) perspective on societal value to an ecosystem perspective on societal value. The article also provides a series of future research agendas that apply stakeholder approaches (i.e., descriptive, instrument, and normative approaches) to ethical marketing in the blockchain-based sharing economy.

The finest theoretical contribution of this research is related to the stakeholder approach (Freeman et al., 2007; Parmar et al., 2010) to ethical marketing in the blockchainbased sharing economy. Importantly, we position BT as an institutional technology that offers a new model of economic coordination and governance in the sharing economy (Davidson et al., 2018), rather than positioning functions as forming another type of technological innovation for digitalization (e.g., a real-time data-sharing infrastructure). Thus, BT could be ethically utilized to serve the best interests of the stakeholders in the ecosystem, and at the same time, abusers can pervert BT and use it for enhancing their market power, as a tool of surveillance, and for the purpose of data monopoly. For this reason, this study identifies in what conditions BT may fulfill the principles of stakeholder capitalism (see Fig. 2). Critically, in "Synthesis and the Shift of Logic Required for Ethical Marketing in the Blockchain-Based Sharing Economy", we demonstrated that BT offers a new vision of capitalism that develops sustainable relationships in the ecosystem in the pursuit of value creation, improves the rights of ownership, and creates positive obligations among the exchange parties-it is a novel form of human institution that is embedded in society and other institutions.
One core limitation is that the current research focuses on a holistic view of how ethical marketing research is explicated in the blockchain-based sharing economy without specifically identifying how research varies across different types of the blockchain ecosystem, such as public versus private blockchain platforms. Thus, future research should draw on stakeholder theory and stakeholder capitalism to investigate how the identified blockchain attributes and capabilities serve to provide a better understanding of the implications for the ethical boundaries of the different blockchain ecosystems. As an ending note, the changes brought about by the blockchain-based sharing economy are equally valid for business customers as they are for consumers/prosumers. Increasingly, business customers are engaged in ethical decision-making, such as designing, innovating, and even manufacturing both their own and bought sustainable offerings in the blockchain-based sharing economy.

Supplementary Information The online version contains supplementary material available at https://doi.org/10.1007/s10551-021-05015-8.

Acknowledgements The authors would like to thank Prashant Kumar for his assistance in co-citation analysis. Finally, the authors are thankful to the associate editor and three anonymous reviewers for their careful reading of our manuscript and their many insightful comments and suggestions.

Author Contributions The first author conceived of the presented idea, developed the theory, performed the systematic literature review analysis, and contributed to the final manuscript "Blockchain Research Among Business Academics" to "Synthesis and the Shift of Logic Required for Ethical Marketing in the Blockchain-Based Sharing Economy". The co-author conceived of the presented idea, discussed the results, and contributed to the final manuscript "The Future Research Directions of the Stakeholder Approach to Ethical Marketing in the Blockchain-Based Sharing Economy". Both authors contributed equally to the Abstracts, Introduction, and Conclusion sections.

Funding Open Access funding provided by University of Oulu including Oulu University Hospital. The first author gratefully acknowledges the financial support from the Foundation for Economic Education (Liikesivistysrahasto) with a Research Grant (18-10683) titled "digitalization-sustainability convergence in business transformation: the perspective of blockchain."

\section{Declarations}

Conflict of interest The authors declare that they have no conflict of interest.

Ethical Approval This article does not contain any studies with human participants or animals performed by any of the authors.

Open Access This article is licensed under a Creative Commons Attribution 4.0 International License, which permits use, sharing, adaptation, distribution and reproduction in any medium or format, as long as you give appropriate credit to the original author(s) and the source, provide a link to the Creative Commons licence, and indicate if changes were made. The images or other third party material in this article are 
included in the article's Creative Commons licence, unless indicated otherwise in a credit line to the material. If material is not included in the article's Creative Commons licence and your intended use is not permitted by statutory regulation or exceeds the permitted use, you will need to obtain permission directly from the copyright holder. To view a copy of this licence, visit http://creativecommons.org/licenses/by/4.0/.

\section{References}

Ahluwalia, S., Mahto, R. V., \& Guerrero, M. (2020). Blockchain technology and startup financing: A transaction cost economics perspective. Technological Forecasting and Social Change, 151,119854

Akerlof, G. (1970). The market for 'lemons': Quality, uncertainty and the market mechanism. The Quarterly Journal of Economics, 84, 488-500.

Aknin, L. B., Whillans, A. V., Norton, M. I., \& Dunn, E. W. (2019). Happiness and prosocial behavior: An evaluation of the evidence. World Happiness Report, Available at: https://world happiness.report/ed/2019/happiness-and-prosocial-behavioranevaluation-of-the-evidence/

Alderson, W., \& Martin, M. W. (1965). Toward a formal theory of transactions and transvections. Journal of Marketing Research, 2(2), 117-127.

Ali, O., Ally, M., \& Dwivedi, Y. (2020). The state of play of blockchain technology in the financial services sector: A systematic literature review. International Journal of Information Management, 54, 102199.

Alkhudary, R., Brusset, X., \& Fenies, P. (2020). Blockchain in general management and economics: A systematic literature review. European Business Review, 32(4), 765-783.

Angel, J. J., \& McCabe, D. (2015). The ethics of payments: Paper, plastic, or Bitcoin? Journal of Business Ethics, 132(3), 603-611.

Areddy, J. T. (2021). China creates its own digital currency, a first for major economy. The World Street Journal, Available at: https:// www.wsj.com/articles/china-creates-its-own-digital-currencya-first-for-major-economy-11617634118

Avital, M. (2018). Peer review: Toward a blockchain-enabled market-based ecosystem. Communications of the Association for Information Systems, 42, 646-653.

Bai, C., \& Sarkis, J. (2020). A supply chain transparency and sustainability technology appraisal model for blockchain technology. International Journal of Production Research, 58(7), 2142-2162.

Bajpai, P. (2019). IBM and Blockchain: What it did in 2018, and where it's going in 2019. Available at: https://www.nasdaq.com/article/ ibm-and-blockchain-what-it-did-in-2018-and-where-its-goingin-2019-cm1100102

Bardhi, F., \& Eckhardt, G. M. (2012). Access-based consumption: The case of car sharing. Journal of Consumer Research, 39(4), 881-898.

Bateman, C. R., Valentine, S., \& Rittenburg, T. (2013). Ethical decision making in a peer-to-peer file sharing situation: The role of moral absolutes and social consensus. Journal of Business Ethics, 115(2), 229-240.

Beck, R., Müller-Bloch, C., \& King, J. L. (2018). Governance in the blockchain economy: A framework and research agenda. Journal of the Association for Information Systems, 19(1), 1020-1034.

Berg, A., Berg, C., Davidson, S., \& Potts, J. (2018). The institutional economics of identity. Retrieved March 13, 2019 from https:// papers.ssrn.com/sol3/papers.cfm?abstract_id=3072823
Bergman, E. M. L. (2012). Finding citations to social work literature: The relative benefits of using Web of Science, Scopus, or Google Scholar. The Journal of Academic Librarianship, 38(6), 370-379.

Böhme, R., Christin, N., Edelman, B., \& Moore, T. (2015). Bitcoin: Economics, technology, and governance. Journal of Economic Perspectives, 29(2), 213-238.

Boukis, A. (2019). Exploring the implications of blockchain technology for brand-consumer relationships: A future research agenda. Journal of Product \& Brand Management, 29(3), 307-320.

Breidbach, C. F., \& Brodie, R. J. (2017). Engagement platforms in the sharing economy: Conceptual foundations and research directions. Journal of Service Theory and Practice, 27(4), 761-777.

Bryans, D. (2014). Bitcoin and money laundering: Mining for an effective solution. Indiana Law Journal, 89(1), 441-472.

Cai, C. W. (2018). Disruption of financial intermediation by FinTech: A review on crowdfunding and blockchain. Accounting and Finance, 58(4), 965-992.

Calvey, M. (2016). Venture capital investing weakens by several measures. San Francisco Business Times, Available at: https://www. bizjournals.com/sanfrancisco/morning_call/2016/08/venturecapital-vc-investing-weakens-fenwick-west.html

Casey, M. J., and Wong, P. (2017). Global supply chains are about to get better, thanks to blockchain. Harvard Business Review, Available at: https://hbr.org/2017/03/global-supply-chainsareabout-to-get-better-thanks-to-blockchain

Catalini, C. (2017). How blockchain applications will move beyond finance. Harvard Business Review. Available at: https://hbr.org/ 2017/03/how-blockchain-applications-will-move-beyond-finance

Catalini, C., \& Gans, J. (2020). Some simple economics of the blockchain. Communication of the ACM. https://doi.org/10.1145/ 3359552

CB Insights (2019). 80+ corporations working on blockchain and distributed ledgers. Available at: https://www.cbinsights.com/resea rch/organizations-corporates-test-blockchains-distributed-ledge rs/

Chong, A. Y. L., Lim, E. T., Hua, X., Zheng, S., \& Tan, C. W. (2019). Business on chain: A comparative case study of five blockchaininspired business models. Journal of the Association for Information Systems, 20(9), 1310-1339.

Christidis, K., \& Devetsikiotis, M. (2016). Blockchains and smart contracts for the Internet of Things. IEEE Access, 4, 2292-2303.

Coase, R. H. (1937). The nature of the firm. Economica, 16(4), 386-405.

Corkery, M. and Popper, N. (2018). From farm to blockchain: Walmart tracks its lettuce. The New York Times. Available at: https://www. nytimes.com/2018/09/24/business/walmart-blockchain-lettuce. html

Crosby, M., Nachiappan, P., Verma, S., \& Kalyanaraman, V. (2016). Blockchain technology: Beyond bitcoin. Applied Innovation Review, 2, 6-19.

Cui, T. H., Ghose, A., Halaburda, H., Iyengar, R., Pauwels, K., Sriram, S., et al. (2020). Informational challenges in omnichannel marketing: Remedies and future research. Journal of Marketing. https://doi.org/10.1177/0022242920968810

Dagnino, G. B., Levanti, G., Minà, A., \& Picone, P. M. (2015). Interorganizational network and innovation: A bibliometric study and proposed research agenda. Journal of Business \& Industrial Marketing, 30, 354-377.

Dai, J., He, N., \& Yu, H. (2019). Utilizing blockchain and smart contracts to enable audit 40: From the perspective of accountability audit of air pollution control in China. Journal of Emerging Technologies in Accounting, 16(2), 23-41.

Dai, J., \& Vasarhelyi, M. A. (2017). Toward blockchain-based accounting and assurance. Journal of Information Systems, 31(3), 5-21. 
Davidson, S., de Filippi, P., \& Potts, J. (2018). Blockchains and the economic institutions of capitalism. Journal of Institutional Economics, 14(4), 639-658.

Di Vaio, A., \& Varriale, L. (2020). Blockchain technology in supply chain management for sustainable performance: Evidence from the airport industry. International Journal of Information Management, 52, 102014.

Dierksmeier, C., \& Seele, P. (2018). Cryptocurrencies and business ethics. Journal of Business Ethics, 152(1), 1-14.

Dierksmeier, C., \& Seele, P. (2020). Blockchain and business ethics. Business Ethics: A European Review, 29(2), 348-359.

Dillon, W. R., \& Goldstein, M. (1984). Multivariate analysis: Methods and applications. Wiley.

Donaldson, T., \& Preston, L. E. (1995). The stakeholder theory of the corporation: Concepts, evidence, and implications. Academy of Management Review, 20(1), 65-91.

Eckhardt, G. M., Houston, M. B., Jiang, B., Lamberton, C., Rindfleisch, A., \& Zervas, G. (2019). Marketing in the sharing economy. Journal of Marketing, 83(5), 5-27.

Egelund-Müller, B., Elsman, M., Henglein, F., \& Ross, O. (2017). Automated execution of financial contracts on blockchains. Business \& Information Systems Engineering, 59(6), 457-467.

European Central Bank (2021). Eurosystem launches digital euro project, European Central Bank Eurosystem, Available at:https:// www. ecb.europa.eu/press/pr/date/2021/html/ecb.pr210 714 d99198ea23.en.html?fbclid=IwAR30P5Ay69VeUhDSMu BlQ-_kiugZbQVRD_KQp8jmPuda_r8kUp12t3bMkhk

Fanning, K., \& Centers, D. (2016). Blockchain and its coming impact on financial services. Journal of Corporate Accounting and Finance, 27(5), 53-57.

Fehrer, J. A., Benoit, S., Aksoy, L., Baker, T. L., Bell, S. J., Brodie, R. J., \& Marimuthu, M. (2018). Future scenarios of the collaborative economy: Centrally orchestrated, social bubbles or decentralized autonomous? Journal of Service Management, 29(5), 859-882.

Feng, H., Wang, X., Duan, Y., Zhang, J., \& Zhang, X. (2020). Applying blockchain technology to improve agri-food traceability: A review of development methods, benefits and challenges. Journal of Cleaner Production. https://doi.org/10.1016/j.jclepro.2020. 121031

Filimonau, V., \& Naumova, E. (2020). The blockchain technology and the scope of its application in hospitality operations. International Journal of Hospitality Management, 87, 102383.

Fisch, C. (2019). Initial coin offerings (ICOs) to finance new ventures. Journal of Business Venturing, 34(1), 1-22.

Francisco, K., \& Swanson, D. (2018). The supply chain has no clothes: Technology adoption of blockchain for supply chain transparency. Logistics, 2(1), 1-13.

Freeman, R. E., Martin, K., \& Parmar, B. (2007). Stakeholder capitalism. Journal of Business Ethics, 74(4), 303-314.

Frizzo-Barker, J., Chow-White, P. A., Adams, P. R., Mentanko, J., Ha, D., \& Green, S. (2020). Blockchain as a disruptive technology for business: A systematic review. International Journal of Information Management, 51, 102029.

Glänzel, W. (2015). Bibliometrics-aided retrieval: Where information retrieval meets scientometrics. Scientometrics, 102(3), 2215-2222.

Grover, P., Kar, A. K., Janssen, M., \& Ilavarasan, P. V. (2019). Perceived usefulness, ease of use and user acceptance of blockchain technology for digital transactions-insights from user-generated content on Twitter. Enterprise Information Systems, 13(6), 771-800.

Gurtu, A., \& Johny, J. (2019). Potential of blockchain technology in supply chain management: A literature review. International Journal of Physical Distribution \& Logistics Management., 49(9), 881-900.
Hair, J. F., Black, W. C., Babin, B. J., \& Anderson, R. E. (2010). Multivariate data analysis: A global perspective (7th ed.). Prentice Hall.

Harvey, C. R., Moorman, C., and Toledo, M. (2018). How blockchain will change marketing as we know it. Working Paper. Available at SSRN 3257511.

Harzing, A. W., \& Alakangas, S. (2016). Google Scholar, Scopus and the Web of Science: A longitudinal and cross-disciplinary comparison. Scientometrics, 106, 787-804.

Hawlitschek, F., Notheisen, B., \& Teubner, T. (2018). The limits of trust-free systems: A literature review on blockchain technology and trust in the sharing economy. Electronic Commerce Research and Applications, 29, 50-63.

Hellwig, K., Morhart, F., Girardin, F., \& Hauser, M. (2015). Exploring different types of sharing: A proposed segmentation of the market for "sharing" businesses. Psychology \& Marketing, 32(9), 891-906.

Hevner, A. R., March, S. T., Park, J., \& Ram, S. (2004). Design science in information systems research. MIS Quarterly, 28(1), 75-105.

Huckle, S., Bhattacharya, R., White, M., \& Beloff, N. (2016). Internet of things, blockchain and shared economy applications. Procedia Computer Science, 98, 461-466.

Hughes, L., Dwivedi, Y. K., Misra, S. K., Rana, N. P., Raghavan, V., \& Akella, V. (2019). Blockchain research, practice and policy: Applications, benefits, limitations, emerging research themes and research agenda. International Journal of Information Management, 49, 114-129.

Hulland, J., \& Houston, M. B. (2020). Why systematic review papers and meta-analyses matter: An introduction to the special issue on generalizations in marketing. Journal of the Academy of Marketing Science, 48, 351-359.

Hyman, M. R., Kopf, D. A., \& Lee, D. (2010). Review of literatureFuture research suggestions: Private label brands: Benefits, success factors and future research. Journal of Brand Management, 17(5), 368-389.

Hyman, M. R., \& Kostyk, A. (2019). Guest editorial: A prospectus on marketing futurology. European Journal of Marketing, 53(8), $1485-1503$.

Hyman, M. R., Tansey, R., \& Clark, J. W. (1994). Research on advertising ethics: Past, present, and future. Journal of Advertising, 23(3), 5-15.

Hyrynsalmi, S., Hyrynsalmi, S. M., and Kimppa, K. K. (2020). Blockchain ethics: A systematic literature review of blockchain research. In International Conference on Well-Being in the Information Society (pp. 145-155). Springer.

Iansiti, M., \& Lakhani, K. R. (2017). The truth about Blockchain. Harvard Business Review, 95, 118-127.

Ilk, N., Shang, G., Fan, S., \& Zhao, J. L. (2021). Stability of transaction fees in Bitcoin: A supply and demand perspective. MIS Quarterly, 45(2), 563-595.

Javalgi, R. G., \& La Toya, M. R. (2018). International marketing ethics: A literature review and research agenda. Journal of Business Ethics, 148(4), 703-720.

Jonas, J. M., Boha, J., Sörhammar, D., \& Moeslein, K. M. (2018). Stakeholder engagement in intra- and inter-organizational innovation. Journal of Service Management, 29(3), 1757-5818.

Kamble, S. S., Gunasekaran, A., \& Gawankar, S. A. (2020). Achieving sustainable performance in a data-driven agriculture supply chain: A review for research and applications. International Journal of Production Economics, 219, 179-194.

Kewell, B., Adams, R., \& Parry, G. (2017). Blockchain for good? Strategic Change, 26(5), 429-437.

Khamitov, M., Grégoire, Y., \& Suri, A. (2020). A systematic review of brand transgression, service failure recovery and product-harm crisis: Integration and guiding insights. Journal of the Academy of Marketing Science, 48, 519-542. 
Kher, R., Terjesen, S., \& Liu, C. (2020). Blockchain, Bitcoin, and ICOs: A review and research agenda. Small Business Economics. https://doi.org/10.1007/s11187-019-00286-y

Kim, H. M., \& Laskowski, M. (2018). Toward an ontology-driven blockchain design for supply-chain provenance. Intelligent Systems in Accounting, Finance and Management, 25(1), 18-27.

Kiviat, T. I. (2015). Beyond Bitcoin: Issues in regulating blockchain transactions. Duke Law Journal, 65, 569-608.

Klarin, A. (2020). The decade-long cryptocurrencies and the blockchain rollercoaster: Mapping the intellectual structure and charting future directions. Research in International Business and Finance, 51, 101067.

Krakovsky, M. (2015). The middleman economy: How brokers, agents, dealers, and everyday matchmakers create value and profit. Palgrave McMillan US.

Kshetri, N. (2017a). Will blockchain emerge as a tool to break the poverty chain in the Global South? Third World Quarterly, $38(8), 1710-1732$.

Kshetri, N. (2017b). Blockchain's roles in strengthening cybersecurity and protecting privacy. Telecommunications Policy, 41(10), 1027-1038.

Kshetri, N. (2018). Blockchain's role in meeting key supply chain management objectives. International Journal of Information Management, 39, 80-89.

Kumar, V. (2018). Transformative marketing: The next 20 years. Journal of Marketing, 82(4), 1-12.

Laczniak, G. R., \& Murphy, P. E. (2006). Normative perspectives for ethical and socially responsible marketing. Journal of Macromarketing, 26(2), 154-177.

Laczniak, G. R., \& Murphy, P. E. (2019). The role of normative marketing ethics. Journal of Business Research, 95, 401-407.

Larios-Hernández, G. J. (2017). Blockchain entrepreneurship opportunity in the practices of the unbanked. Business Horizons, 60(6), 865-874.

Le Vine, S., Lee-Gosselin, M., Sivakumar, A., \& Polak, J. (2014). A new approach to predict the market and impacts of round-trip and point-to-point carsharing systems: Case study of London. Transportation Research Part d: Transport and Environment, $32,218-229$

Lemieux, V. (2016). Trusting records: Is blockchain technology the answer. Records Management Journal, 26(2), 110-139.

Li, K., Lee, J. Y., \& Gharehgozli, A. (2021). Blockchain in food supply chains: A literature review and synthesis analysis of platforms, benefits and challenges. International Journal of Production Research. https://doi.org/10.1080/00207543.2021. 1970849

Lu, Q., \& Xu, X. (2017). Adaptable blockchain-based systems: A case study for product traceability. IEEE Software, 34(6), $21-27$.

Lumineau, F., Wang, W., \& Schilke, O. (2021). Blockchain governance-A new way of organizing collaborations? Organization Science, 32(2), 500-521.

Mainelli, M., \& Smith, M. (2016). Sharing ledgers for sharing economies: An exploration of mutual distributed ledgers (aka blockchain technology). The Journal of Financial Perspectives: Fintech, 3(3), 1-44.

Malherbe, L., Montalban, M., Bédu, N., \& Granier, C. (2019). Cryptocurrencies and blockchain: Opportunities and limits of a new monetary regime. International Journal of Political Economy, 48(2), 127-152.

Martin, E., \& Susan, S. (2011). The impact of carsharing on public transit and non-motorized travel: An exploration of North American carsharing survey data. Energies, 4(12), 2094-2114.

Martindale, W., Hollands, T., Swainson, M., \& Keogh, J. G. (2018). Blockchain or bust for the food industry? Food Science and Technology, 33(4), 41-45.
McGrath, R. G. (2013). The end of competitive advantage: How to keep your strategy moving as fast as your business. Harvard Business Review Press.

Mendling, J., Decker, G., Hull, R., Reijers, H. A., \& Weber, I. (2018). How do machine learning, robotic process automation, and blockchains affect the human factor in business process management? Communications of the Association for Information Systems, 43(1), 1-23.

Min, H. (2019). Blockchain technology for enhancing supply chain resilience. Business Horizons, 62(1), 35-45.

Min, S., Zacharia, Z. G., \& Smith, C. D. (2019). Defining supply chain management: In the past, present, and future. Journal of Business Logistics, 40(1), 44-55.

Mollick, E. (2014). The dynamics of crowdfunding: An exploratory study. Journal of Business Venturing, 29(1), 1-16.

Momtaz, P. P. (2020). CEO emotions and firm valuation in initial coin offerings: An artificial emotional intelligence approach. Strategic Management Journal. https://doi.org/10.1002/smj.3235

Mougayar, W. (2016). The business blockchain: Promise, practice, and application of the next internet technology. Wiley.

Narayanan, A., Bonneau, J., Felten, E., Miller, A., \& Goldfeder, S. (2016). Bitcoin and cryptocurrency technologies: A comprehensive introduction. Princeton University Press.

Nieto-Martin, J., Blaise, A. L., \& Varga, L. (2019). Community energy retail tariffs in Singapore: Opportunities for peer-to-peer and time-of-use versus vertically integrated tariffs. Journal of Energy Markets, 12(2), 71-99.

Nowiński, W., \& Kozma, M. (2017). How can blockchain technology disrupt existing business models?". Entrepreneurial Business and Economics Review, 5(3), 173-188.

Ølnes, S., Ubacht, J., \& Janssen, M. (2017). Blockchain in government: Benefits and implications of distributed ledger technology for information sharing. Government Information Quarterly, 34(3), $355-364$.

Pan, X., Pan, X., Song, M., Ai, B., \& Ming, Y. (2020). Blockchain technology and enterprise operational capabilities: An empirical test. International Journal of Information Management, 52, 101946.

Parmar, B. L., Freeman, R. E., Harrison, J. S., Wicks, A. C., Purnell, L., \& De Colle, S. (2010). Stakeholder theory: The state of the art. Academy of Management Annals, 4(1), 403-445.

Pawczuk, L., Massey, R., and Schatsky, D. (2018). Breaking blockchain open: Deloitte's 2018 global blockchain survey. Deloitte. Retrieved from https://www2.deloitte.com/content/dam/Deloitte/ cz/Documents/financial-services/cz-2018-deloitte-global-block chain-survey.pdf

Pazaitis, A., De Filippi, P., \& Kostakis, V. (2017). Blockchain and value systems in the sharing economy: The illustrative case of Backfeed. Technological Forecasting and Social Change, 125, 105-115.

Pelt, R. V., Jansen, S., Baars, D., \& Overbeek, S. (2021). Defining blockchain governance: A framework for analysis and comparison. Information Systems Management, 38(1), 21-41.

Perren, R., \& Kozinets, R. V. (2018). Lateral exchange markets: How social platforms operate in a networked economy. Journal of Marketing, 82(1), 20-36.

Peters, G. W., \& Panayi, E. (2016). Understanding modern banking ledgers through blockchain technologies: Future of transaction processing and smart contracts on the Internet of money. Banking beyond banks and money (pp. 239-278). Springer.

Pólvora, A., Nascimento, S., Lourenço, J. S., \& Scapolo, F. (2020). Blockchain for industrial transformations: A forward-looking approach with multi-stakeholder engagement for policy advice. Technological Forecasting and Social Change, 157, 120091.

Pournader, M., Shi, Y., Seuring, S., \& Koh, S. L. (2020). Blockchain applications in supply chains, transport and logistics: A 
systematic review of the literature. International Journal of Production Research, 58(7), 2063-2081.

Queiroz, M. M., Telles, R., \& Bonilla, S. H. (2019). Blockchain and supply chain management integration: A systematic review of the literature. Supply Chain Management an International Journal, 25(2), 241-254.

Ramaswamy, V., \& Ozcan, K. (2016). Brand value co-creation in a digitalized world: An integrative framework and research implications. International Journal of Research in Marketing, 33(1), 93-106.

Randhawa, K., Wilden, R., \& Hohberger, J. (2016). A bibliometric review of open innovation: Setting a research agenda. Journal of Product Innovation Management, 33, 750-772.

Rashideh, W. (2020). Blockchain technology framework: Current and future perspectives for the tourism industry. Tourism Management, 80, 104125.

Rejeb, A., Keogh, J. G., \& Treiblmaier, H. (2020). How blockchain technology can benefit marketing: Six pending research areas. Frontiers in Blockchain. https://doi.org/10.3389/fbloc.2020. 00003

Reyna, A., Martin, C., Chen, J., Soler, E., \& Diaz, M. (2018). On blockchain and its integration with IoT. Challenges and opportunities. Future Generation Computer Systems, 88, 173-190.

Risius, M., \& Spohrer, K. (2017). A blockchain research frameworkWhat we (don't) know, where we go from here, and how we will get there. Business \& Information Systems Engineering, 59(6), 385-409.

Rogers, E. M. (1995). Diffusion of innovations (4th ed.). Free Press.

Rossi, M., Mueller-Bloch, C., Thatcher, J. B., \& Beck, R. (2019). Blockchain research in information systems: Current trends and an inclusive future research agenda. Journal of the Association for Information Systems, 20(9), 1390-1405.

Saberi, S., Kouhizadeh, M., Sarkis, J., \& Shen, L. (2019). Blockchain technology and its relationships to sustainable supply chain management. International Journal of Production Research, 57(7), $2117-2135$

Schlegelmilch, B. B., \& Öberseder, M. (2010). Half a century of marketing ethics: Shifting perspectives and emerging trends. Journal of Business Ethics, 93(1), 1-19.

Schor, J. (2016). Debating the sharing economy. Journal of Self-Governance and Management Economics, 4(3), 7-22.

Scott, B., Loonam, J., \& Kumar, V. (2017). Exploring the rise of blockchain technology: Towards distributed collaborative organisations. Strategic Change, 26(5), 423-428.

Seibold, S. \& Samman, G. (2016). Consensus Immutable agreement for the Internet of value, KPMG. Available at: https://assets.kpmg/ content/dam/kpmg/pdf/2016/06/kpmg-blockchain-consensusmechanism.pdf?utm_content=buffer84bc3\&utm_medium=socia $1 \& u t m \_$source $=$twitter.com\&utm_campaign $=$buffer

Semuels, A. (2018). What happens when gig economy workers become employees?. The Atlantic, Available at: https://www.theatlantic. com/technology/archive/2018/09/gig-economy-independentcontractors/570307/

Shim, J. P., Avital, M., Dennis, A. R., Rossi, M., Sørensen, C., \& French, A. (2019). The transformative effect of the internet of things on business and society. Communications of the Association for Information Systems, 44(1), 5.

Sikorski, J. J., Haughton, J., \& Kraft, M. (2017). Blockchain technology in the chemical industry: Machine-to-machine electricity market. Applied Energy, 195, 234-246.

Sisson, P. (2018). Are Uber and Lyft helping or hurting public transit?. Curbed Available at: www.curbed.com/2018/5/8/17330846/uberlyft-mass-transit-bus-transportation
Small, H. (1973). Co-citation in the scientific literature: A new measure of the relationship between two documents. Journal of the American Society for Information Science, 24, 265-269.

Storbacka, K. (2019). Actor engagement, value creation and market innovation. Industrial Marketing Management, 80, 4-10.

Storbacka, K., Brodie, R. J., Böhmann, T., Maglio, P. P., \& Nenonen, S. (2016). Actor engagement as a microfoundation for value cocreation. Journal of Business Research, 69(8), 3008-3017.

Sutherland, W., \& Jarrahi, M. H. (2018). The sharing economy and digital platforms: A review and research agenda. International Journal of Information Management, 43, 328-341.

Tan, T. M., \& Saraniemi, S. (2021). Integrative model of stakeholder well-being and engagement in a permissioned blockchain ecosystem. Oulu Business School: University of Oulu, Working paper.

Tan, T. M., Salo, J., Ahokangas, P., Seppänen, V., \& Sandner, P. (2020). Revealing the disintermediation concept of blockchain technology: How intermediaries gain from blockchain adoption in a new business model? In R. C. Ho, M. Nurallah, \& H. H. Ng (Eds.), Impact of globalization and advanced technologies on online business models. IGI-Global.

Tandon, A., Dhir, A., Islam, N., \& Mäntymäki, M. (2020). Blockchain in healthcare: A systematic literature review, synthesizing framework and future research agenda. Computers in Industry, 122, 103290.

Tang, Y., Xiong, J., Becerril-Arreola, R., \& Iyer, L. (2020). Ethics of blockchain. Information Technology \& People, 33(2), 602-632.

Tapscott, D., \& Tapscott, A. (2016). Blockchain revolution: How the technology behind Bitcoin is changing money, business, and the world. Penguin.

Tapscott, D., \& Tapscott, A. (2017). How blockchain will change organizations. MIT Sloan Management Review, 58(2), 10-13.

Thakor, A. V. (2020). Fintech and banking: What do we know? Journal of Financial Intermediation, 41, 10033.

Tiscini, R., Testannata, S., Ciaburri, M., \& Ferrari, E. (2020). The blockchain as a sustainable business model innovation. Management Decision, 58(8), 1621-1642.

Trbovich, A. S. (2019). In pursuit of good governance for the energy industry blockchain. Journal of Energy Markets, 12(2), 1-17.

Treiblemaier, H. (2018). The impact of the blockchain on the supply chain: A theory-based research framework and a call for action. Supply Chain Management: International Journal, 23(6), $545-559$.

Tshering, G., \& Gao, S. (2020). Understanding security in the government's use of blockchain technology with value focused thinking approach. Journal of Enterprise Information Management, 33(3), 519-540.

Tsiulin, S., Reinau, K. H., Hilmola, O. P., Goryaev, N., \& Karam, A. (2020). Blockchain-based applications in shipping and port management: A literature review towards defining key conceptual frameworks. Review of International Business and Strategy, $30(2), 201-224$.

Unalan, S., \& Ozcan, S. (2020). Democratising systems of innovations based on Blockchain platform technologies. Journal of Enterprise Information Management, 33(6), 1511-1536.

Underwood, S. (2016). Blockchain beyond Bitcoin. Communications of the ACM, 59(11), 15-17.

Upadhyay, N. (2020). Demystifying blockchain: A critical analysis of challenges, applications and opportunities. International Journal of Information Management, 54, 102120.

Vargo, S. L., \& Lusch, R. F. (2017). Service-dominant logic 2025. International Journal of Research in Marketing, 34(1), 46-67.

Veuger, J. (2018). Trust in a viable real estate economy with disruption and blockchain. Facilities, 36(1/2), 103-120.

Walker, J. T., Fenton, E., Salter, A., \& Salandra, R. (2019). What influences business academics' use of the association of business 
schools (ABS) list? Evidence from a survey of UK academics. British Journal of Management, 30(3), 730-747.

Wamba, S. F., \& Queiroz, M. M. (2020). Blockchain in the operations and supply chain management: Benefits, challenges and future research opportunities. International Journal of Information Management, 52, 102064.

Wang, Y., Han, J. H., \& Beynon-Davies, P. (2019). Understanding blockchain technology for future supply chains: A systematic literature review and research agenda. Supply Chain Management an International Journal, 24(1), 62-84.

White, H. D., \& Griffith, B. C. (1981). Author cocitation: A literature measure of intellectual structure. Journal of the Association for Information Science \& Technology, 32, 163-171.

Wight, M. (2018). Maersk and IBM struggling to find partners: The TradeLens platform was launched earlier this year. Blockchain Land, Available at: https://theblockchainland.com/2018/10/30/ maersk-and-ibm-struggling-to-find-partners/

Williamson, O. E. (1979). Transaction cost economics: The governance of contractual relations. The Journal of Law and Economics, 22(2), 233-261.

Williamson, O. E. (1985). The economic institutions of capitalism. Free Press.

Wolfson, R. (2018). A first for Manhattan: $\$ 30 M$ real estate property tokenized with blockchain. Forbes, Available at: https://www. forbes.com/sites/rachelwolfson/2018/10/03/a-first-for-manha $\operatorname{ttan}-30 \mathrm{~m}$-real-estate-property-tokenized-with-blockchain/? $\mathrm{sh}=$ 267379 bd 4895

Xu, L. D., Xu, E. L., \& Li, L. (2018). Industry 4.0: state of the art and future trends. International Journal of Production Research, 56(8), 2941-2962.

Yeoh, P. (2017). Regulatory issues in blockchain technology. Journal of Financial Regulation and Compliance., 25(2), 196-208.
Yermack, D. (2017). Corporate governance and blockchains. Review of Finance, 21(1), 7-31.

Ying, W. C., Jia, S. L., \& Du, W. Y. (2018). Digital enablement of blockchain: Evidence from HNA group. International Journal of Information Management, 39(4), 1-4.

Yli-Huumo, J., Choi, D., Ko, S., Park, S., \& Smolander, K. (2016). Where is current research on blockchain technology?-A systematic review. PLoS ONE, 11, 1-27.

Zhang, J., Yu, Q., Zheng, F., Long, C., Lu, Z., \& Duan, Z. (2016). Comparing keywords plus of WOS and author keywords: A case study of patient adherence research. Journal of the Association for Information Science and Technology, 67(4), 967-972.

Zhao, G., Liu, S., Lopez, C., Lu, H., Elgueta, S., Chen, H., \& Boshkoska, B. M. (2019). Blockchain technology in agri-food value chain management: A synthesis of applications, challenges and future research directions. Computers in Industry, 109, 83-99.

Zheng, Z., Xie, S., Dai, H. N., Chen, X., \& Wang, H. (2018). Blockchain challenges and opportunities: A survey. International Journal of Web and Grid Services, 14(4), 352-375.

Zhou, K., Allen, B. J., Gretz, R., \& Houston, M. B. (2019). When do the best service agents decrease customer retention? An investigation of online service platforms and platform exploitation. Working paper, University of Texas at San Antonio.

Zhu, S., Song, M., Lim, M. K., Wang, J., \& Zhao, J. (2020). The development of energy blockchain and its implications for China's energy sector. Resources Policy, 66, 101595.

Publisher's Note Springer Nature remains neutral with regard to jurisdictional claims in published maps and institutional affiliations. 